\title{
Importance of integrin receptors in the field of pharmaceutical \& medical science
}

\author{
Sumit Goswami \\ Pfizer, Inc. BioTherapeutics Pharmaceutical Sciences, Chesterfield, USA \\ Email: sumit.goswami@pfizer.com
}

Received 12 January 2013; revised 13 March 2013; accepted 17 April 2013

Copyright (C) 2013 Sumit Goswami. This is an open access article distributed under the Creative Commons Attribution License, which permits unrestricted use, distribution, and reproduction in any medium, provided the original work is properly cited.

\begin{abstract}
Integrin receptors have remained as a key subject of interest in the pharmaceutical industry for the last few years. There are a total of 24 different types of integrin heterodimers. Each of these heterodimers plays important role in various biological processes that are inherent to different pathological conditions. As a result, integrin receptors have been extensively evaluated for their role in therapeutic targeting. There are different classes of inhibitors against integrin receptors and this review provides an overview on different classes of integrin inhibitors that are currently available. A number of review articles have been written on the possible application of integrin receptors in therapeutic targeting. Many of these articles have heavily emphasized on the importance of

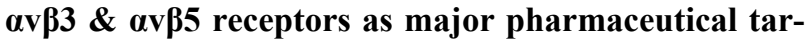
get in cancer but little emphasis has been given on the importance of other integrin receptors, such as $\alpha 5 \beta 1$, $\alpha I I b \beta 3, \alpha 4 \beta 7, \alpha v \beta 6$ etc. While this review gives due importance to both $\alpha v \beta 3 \&$ av $\beta 5$ receptors and provides an historical perspective on how these two receptors have evolved as a potential target for cancer, significant emphasis has also been given on the other integrin receptors that have started enjoying the status of important drug target over the course of last few years. Effort has been maintained to discuss briefly on the key physiological basis of their importance as drug target. For example, involvement of $\alpha v \beta 3$ in angiogenesis has made it a therapeutic target for the treatment of cancer. At the same time expression of this receptor on the surface of osteoclast has made it a target for the treatment of osteoporosis. Thus, emphasis has been given on discussing the role of the integrin receptors in different disease conditions followed by specific examples of drug molecules that have been trialed against these receptors. While hundreds of candidate molecules have been developed
\end{abstract}

against different integrin receptors only a handful of them has been subject to phase-III clinical trial. That necessitates careful consideration of certain concerns that are associated with direct targeting of integrins and thus has also been an important goal of this review. In the last few years application of integrin receptors have extended beyond mere therapeutic targeting. Several integrin receptors are currently are studied for their potential of aiding at diagnostic imaging and drug delivery. In this review a brief overview has also been provided on how integrin are being targeted for diagnostic imaging and drug delivery with relevant examples. Thus the primary aim of this review has been to provide an comprehensive overview on the broad scope of application that integrin receptors have in the field of medical science.

Keywords: Integrin Receptors; Therapeutic Targeting; Diagnosic Imaging; Drug Delivery

\section{INTRODUCTION}

Integrins are cell surface receptors that are primarily involved in integrating the extracellular environment to the intracellular environment as the name suggest [1-3]. In the last two decades integrins have generated tremendous interest among the scientists. A myriad of articles are being published every year, yet the intricate complexity and diversity of integrin function is continuing to challenge the scientific world.

There are a total of 24 different types of integrins [4]. The integrin family of receptors, depending on their ligand recognition pattern can be broadly classified into four different categories-I) RGD binding, II) collagen binding, III) laminin binding, and IV) leukocyte binding types of integrins (Figure 1, adapted from Barczyk et al., 2010). In the last decade, significant advancements have been made in our understanding of integrin structure. 


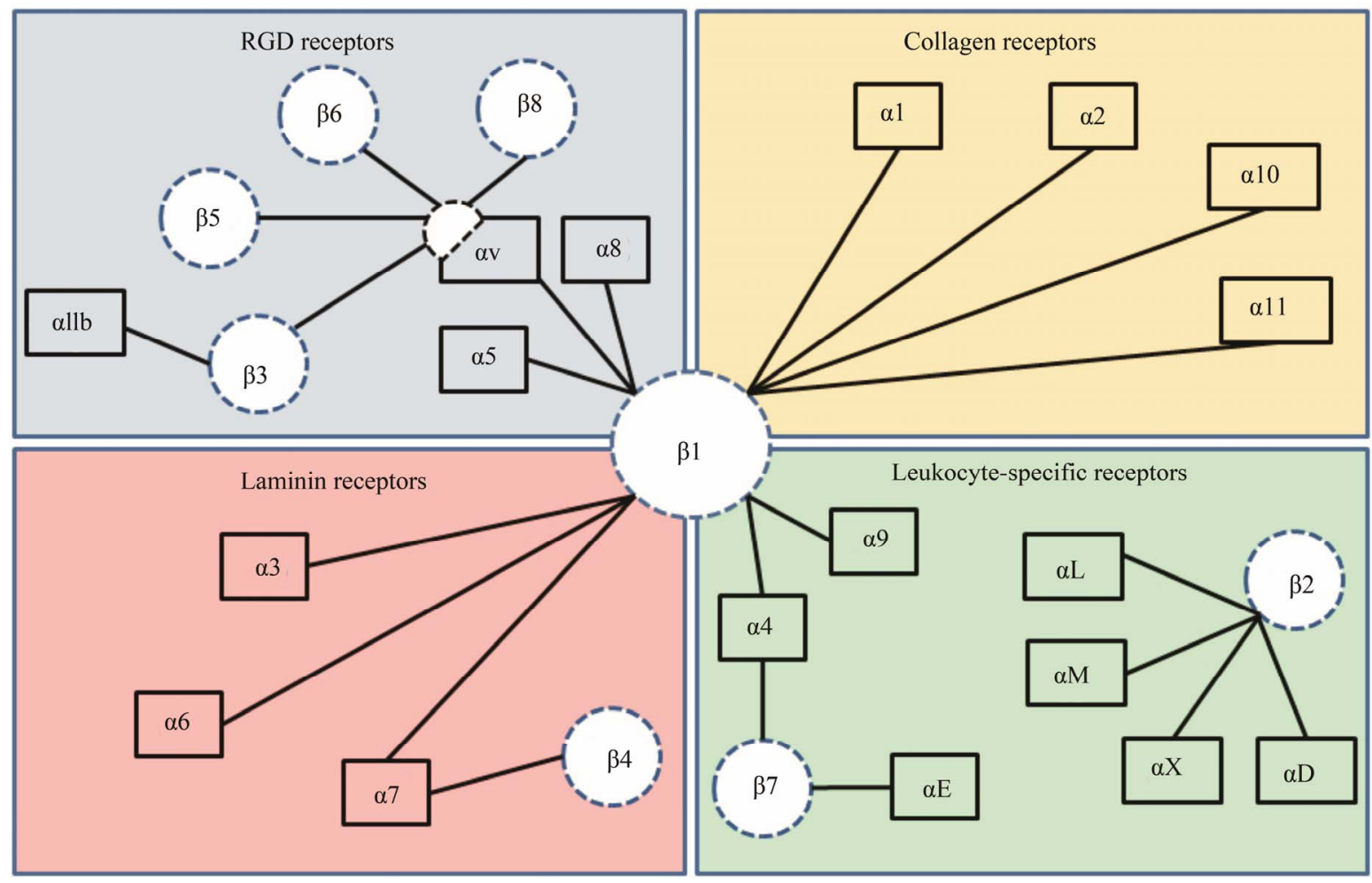

Figure 1. This figure includes the classification of integrin receptors based on their ligand binding ability. Four different categories are presented: (a) RGD binding, (b) collagen binding, (c) laminin binding and, (d) leukocyte binding. $\beta 1$-subunit is known to heterodimerize with eleven different kinds of $\alpha$-subunits. While most of $\alpha$-subunits pair up with one kind of $\beta$-subunit, $\alpha v$ - and $\alpha 4$-subunits are the exception.

A schematic representation of the integrin heterodimer is shown in Figure 2. Each subunit is made of multiple domains. The $\alpha$-subunit contains a 7-bladed $\beta$-propeller domain, followed by a thigh, a calf- $1 \&$ a calf- 2 domain. The last three or four blades of the $\beta$-propeller domain contains an EF-hand motif for $\mathrm{Ca}^{2+}$ binding $[4,5]$. There are a total of about 9 integrins that contain an additional $\alpha \mathrm{I}$-domain (or $\alpha \mathrm{A}$-domain) that sits on top of the $\beta$-propeller domain. This $\alpha$ I-domain possesses a Rossman fold containing a central $\beta$-sheet (five parallel $\beta$-strands and one anti-parallel $\beta$-strand) surrounded by seven $\alpha$-helices and is inserted between the $2^{\text {nd }}$ and $3^{\text {rd }}$ blade of the $\beta$-propeller domain [6,7]. For integrins that contain the $\alpha \mathrm{I}$-domain, the ligand binding pocket is included within the $\alpha \mathrm{I}$-domain. For integrins that do not contain $\alpha \mathrm{I}$-domain (e.g. $\alpha \mathrm{v} \beta 3$ ), the ligand binding pocket is made of the interface formed between the $\beta$-propeller domain of the $\alpha$-subunit and $\beta$ A-domain (or $\beta$ I-domain) of the $\beta$-subunit [5], as shown in Figure 2. The crystal structure of $\alpha v \beta 3$ in its RGD ligand-bound form showed that the ligand was indeed present at the interface. Besides the $\beta$ A-domain, the $\beta$-subunit also contains other domains such as a hybrid domain, a plexin-semaphorin-integrin (PSI) domain, four epidermal growth factor repeats (EGF1-4) and a $\beta$-tail domain $[5,8,9]$.

Integrin signaling is unique among all the cell surface receptors because signaling can propagate in both directions (outside to inside and inside to outside). Most of the time, cell surface receptor-mediated signaling involves initial binding of the ligand on the extracellular domain, which then initiates changes at the cytoplasmic domain leading to further propagation of signaling events; this is called outside-in signaling. Integrin receptors participate in another kind of signaling process called inside-out signaling. In this process, binding of intracellular ligands to the cytoplasmic domain results in some conformational change in the extracellular domain of the receptor that in turn modulates its ligand binding characteristics $[10,11]$. Integrin binding to its ligand (both extracellular and intracellular) is thus highly regulated and is involved in several cell-signaling processes. As a result, integrins play major roles in regulating different biological processes, such as differentiation, cell survival, apoptosis, cell-cycle regulation etc. [12]. Integrin's involvement in several biological processes has caused them play extremely important role in various pathological conditions. As a result, in the last few years integrins have received tremendous attention for both therapeutic and medical application. The main goal of this review is to explore how integrins are being therapeutically targeted for the treatment of different pathological conditions and how integrins are being utilized for other medical purposes, 


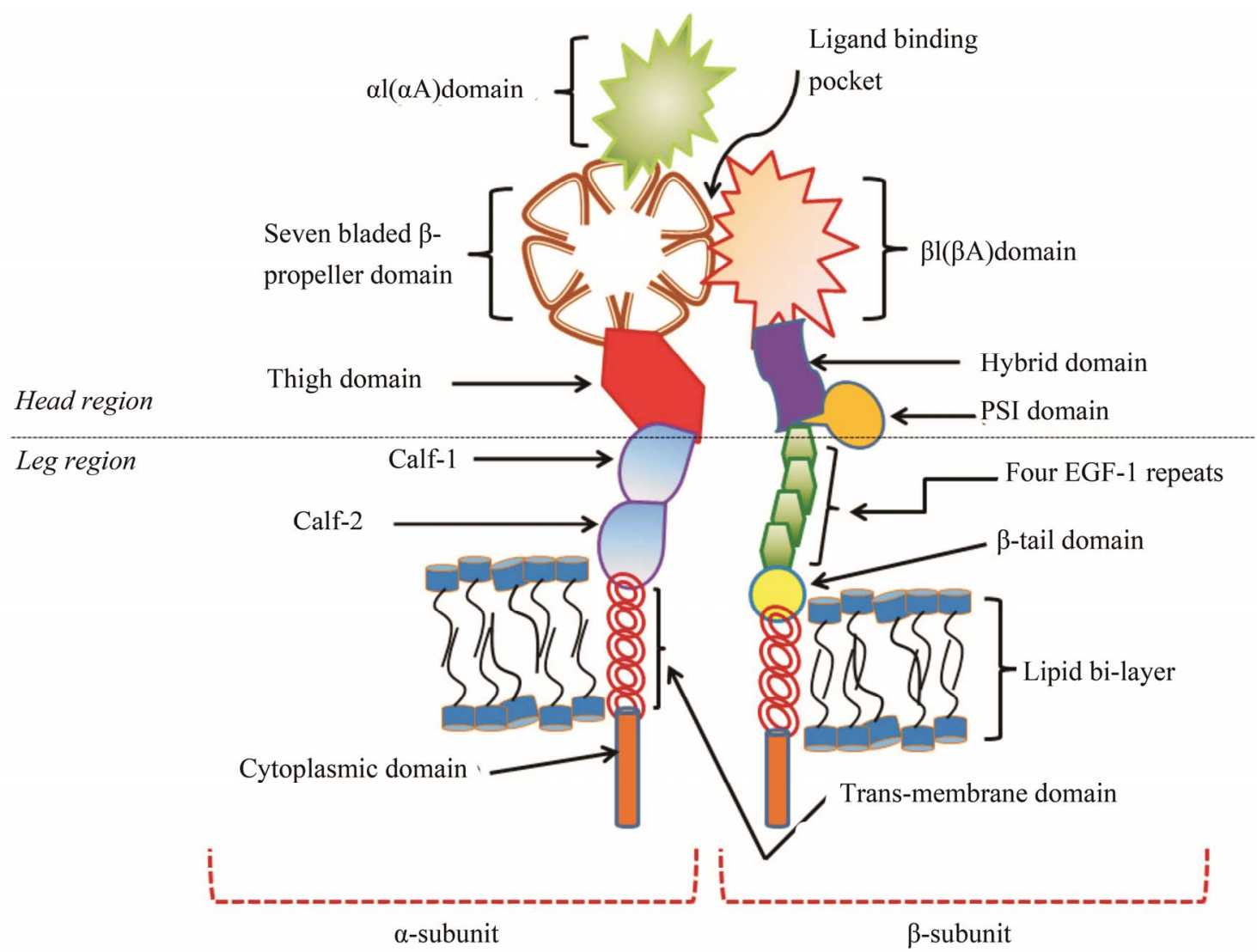

Figure 2. Representation of prototype $\alpha \mathrm{I}$-domain containing integrin heterodimer. $\alpha \mathrm{I}(\alpha \mathrm{A})$-domain is part of the $\alpha$-subunit and connected to the seven-bladed $\beta$-propeller domain. There are nine different types of integrins that contain $\alpha$ I domain. This domain contains Rossman fold and a MIDAS site for metal ion binding. $\beta$-propeller domain contains EF-hand motif for calcium binding and is connected with thigh domain followed by calf- 1 and calf- 2 domains. $\beta$-subunit contains a $\beta \mathrm{I}(\beta \mathrm{A})$-domain that posses structural similarity with $\alpha \mathrm{I}$ domain. This domain also contains Rossman fold and MIDAS site for metal ion binding. The interface of $\beta$ I domain of $\beta$-subunit and $\beta$-propeller domain of $\alpha$-subunit forms a ligand binding pocket. $\beta \mathrm{I}$-domain is connected to hybrid domain followed by a plexin-somaphorin-integrin (PSI) domain, four EGF repeats and a $\beta$-tail domain.

such as diagnostic imaging and targeted drug delivery.

\section{MODE OF USE IN MEDICAL SCIENCE}

\subsection{Direct Therapeutic Targeting}

Integrin receptors are functionally involved with many different biological processes that are common to both body homeostasis and pathological conditions. For example, angiogenesis is a biological process that plays important role in both development and several pathological conditions such as wound healing and cancer. In fact, several studies indicate that activated endothelial cells that are involved in tumor angiogenesis show high level of expression of $\alpha v \beta 3 \& \alpha v \beta 5$, which are not highly expressed in the quiescent endothelial cells [13]. Inhibition of the interaction of $\alpha v \beta 3 \& \alpha v \beta 5$ with their ligands has been targeted for blocking endothelial cell-mediated angiogenesis associated with tumor growth and survival. Not only that, $\alpha v \beta 3$ \& $\alpha v \beta 5$ have been implicated in several other pathological conditions such as rheumatoid arthritis, osteoporosis etc. $[14,15]$. Besides these two integrin receptors, there are several other integrins that are involved in various kinds of disease. For example, $\alpha 4 \beta 7$ is involoved in inflammatory bowel disease [16] and $\alpha 5 \beta 1$ has been implicated in tumor development [17], to name a few.

Every day, new information is being generated on the specific roles that integrins are playing at the molecular level in different pathological conditions. As a result, in last few years drug companies have shown significant interest in designing inhibitors targeting specific integrin ligand interaction. In this section of the review, we will start with a brief discussion on the classification of integrin inhibitors that are available, followed by discussion on various integrins that are being directly targeted and their role in different pathological conditions.

\subsubsection{Classification of Anti-Integrin Drugs}

Currently, all the anti-integrin drugs that are being mar- 
keted or under the process of development are designed to specifically block the interaction of integrins with their ligands. These drugs can be broadly classified into three major categories. These are as follows-1) monoclonal antibodies, 2) peptide inhibitors, and 3) small molecule inhibitors. Each of these categories will be briefly discussed to obtain some ideas on their design and functionality. Table 1 has a list of different types of integrin inhibitors that have been subject to clinical trial. The main purpose of this table is to provide an idea on how extensively this group of receptors has been targeted for therapeutic application. A comprehensive overview on the clinical trial status of all the integrin based on inhibittors has been provided in an excellent review by Goodman et al. [18]. About 72 trials are still active where as 46 trials have been discontinued. There are about 140 clinical trials on which no development has been reported for about 15 years. The number of commercially approved integrin based inhibitors is four [18].

\section{1) Monoclonal Antibodies}

From the time the drug companies started showing interest in protein based drugs, monoclonal antibodies $(\mathrm{mAb})$ have garnered significant attention. There are a number of FDA approved mAb based therapies that are currently being marketed. For example, Avastin (Bevacizumab), a monoclonal antibody against Vascular endothelial growth factor-A (VEGF-A), was the first commercially available $\mathrm{mAb}$ based angiogenesis inhibitor. Additionally, there is a monoclonal antibody against integrin $\alpha \operatorname{Ilb} \beta 3$, called REOPRO/Abciximab, that is currently being marketed for the treatment of myocardial infarction and unstable angina. There are also a number of other mAb based integrin inhibitors that are currently undergoing different phases of clinical trials.

Tremendous biological importance of integrin receptors has led to the development of a large number of antibodies against them. Byron et al. have provided a comprehensive list of these mAbs in a wonderful short review on anti-integrin mAbs [19]. Integrin antibodies are of three different types. The first type is the stimulatory or activation specific mAbs that binds to the activated high affinity ligand binding state of integrin and shifts the equilibrium towards such high affinity state and the second type is the nonfunctional mAbs that do not affect the functionality of integrins [19]. But the last type, which is an inhibitory type of mAb, has gained maximum importance as the target for possible therapeutic intervention. Some of these inhibitory types of antibodies are known to directly block ligand binding, whereas some of them act as an allosteric inhibitor of ligand binding. One example of an allosteric inhibitor is mAb13 against $\beta 1$ integrin [20]. Many of these inhibitory antibodies bind to the head domain of heterodimeric integrin molecules, formed by the contact between the $\beta$ A-do- main of the $\beta$-subunit and the $\beta$-propeller domain of the $\alpha$-subunit (with or without the I-domain). For example, Abciximab (anti- $\alpha \operatorname{Ilb} \beta 3 \mathrm{mAb}$ ) binds to the top face of the $\beta A$-domain of the $\beta 3$-subunit [21]. mAbs that are currently undergoing clinical trial or being marketed are humanized, in order to avoid the possible conflict with our immune system. Many of those anti-integrin mAbs that were initially found to be useful in preclinical studies were made in mice. The $\mathrm{Fc}$ portions of these $\mathrm{mAb}$ were replaced with the Fc portion of human IgG (humanized) before they were subject to clinical trial. One example is LM609, which is a murine anti- $\alpha \mathrm{v} \beta 3 \mathrm{mAb}$ and was found to be extremely useful in inhibiting tumor progression and angiogenesis in preclinical studies. A humanized version of this antibody known as Vitaxin is currently undergoing clinical trial for the treatment of colorectal cancer and prostate cancer. Among the inhibitory antibodies that are known to directly block ligand binding, one special kind requires brief mentioning. This type of blocking antibody is known as a "ligand mimetic", because they possess an epitope in their variable region that is usually found in the natural ligand of the target integrin. One example is 6.8G6, an antibody against $\alpha v \beta 6$ that contains a RGD motif in the complementarity determining region-3 (CDR-3) domain of the heavy chain [22]. 16N7C2 is another example of a ligand mimetic $\mathrm{mAb}$ that acts against $\alpha \operatorname{IIb} \beta 3$ [23].

\section{2) Peptide Inhibitors}

Peptide-based inhibitor of integrins is another class of inhibitor that has gained potential interest. Among the peptide inhibitors of integrins the most important type are the RGD-based inhibitors. Integrins can be broadly classified in four different types based on their ligand recognition pattern as mentioned before. These are collagen binding, laminin binding, RGD binding \& leukocyte associated ligand binding [24]. RGD is a tripeptide sequence that is very commonly found in many components of extracellular matrices, e.g. vitronectin, fibronectin, fibrinogen etc. [4]. There are eight different integrins that recognize RGD sequence in their natural ligands such as $\alpha \mathrm{v} \beta(1,3,5,6,8), \alpha \operatorname{IIb} \beta 3, \alpha 5 \beta 1$ and $\alpha 8 \beta 1$ [25]. In 2002 Xiong et al. reported the crystal structure of a full length soluble integrin $\alpha v \beta 3$ with its ligand cyclic-RGD [26]. In this structure it was clearly shown that the RGD sequence directly interacts with the crevice formed between the $\beta$-propeller domain of $\alpha \mathrm{v}$-subunit and the $\beta A$ domain of the $\beta 3$-subunit in the head domain of this hetero-dimer. As expected, the RGD peptide has been used quite commonly and successfully for blocking integrin-mediated cellular binding and migration in in vitro assays. The crystal structure showed that each amino acid of this tri-peptide sequence was making significant contact in the head region. Indeed, replacement of the Glycine (RAD) residue with an Alanine resulted in 
Table 1. Inhibitors of integrin receptors.

\begin{tabular}{|c|c|c|c|c|}
\hline Inhibitors & Type & Target integrin & Route of application & Current status \\
\hline C7E3/abciximab/REOPRO & Humanized mAb & $\alpha \operatorname{IIb} \beta 3$ & IV & Marketed as a drug in Myocardial infarction \\
\hline Vitaxin-II/abegrin/Med-522 & Humanized $\mathrm{mAb}$ & $\alpha v \beta 3$ & IV & $\begin{array}{l}\text { Phase-II clinical trial for the treatment of } \\
\text { stage-IV metastatic melanoma, colorectal } \\
\text { cancer, androgen-independent-prostate } \\
\text { cancer and RA has been completed }\end{array}$ \\
\hline CNTO 95 & Humanized $\mathrm{mAb}$ & $\alpha v \beta 3, \alpha v \beta 5$ & IV & $\begin{array}{l}\text { Phase-I clinical trial in patients with solid } \\
\text { tumors and refractory prostate cancer has } \\
\text { been found to be safe and well tolerated. } \\
\text { Phase-II clinical trials in combination with } \\
\text { docetaxel and prednisolone for the treatment } \\
\text { of metastatic hormone refractory prostate } \\
\text { cancer patients is ongoing }\end{array}$ \\
\hline Natalizumab/Tysabri & Humanized $\mathrm{mAb}$ & $\alpha 4 \beta 1, \alpha 4 \beta 7$ & IV & $\begin{array}{l}\text { Currently being clinically used for the } \\
\text { treatment of MS and CD } \\
\text { phase-II clinical trial for the treatment of RA } \\
\text { has been terminated }\end{array}$ \\
\hline Vedolizumab/MLN-002 & Humanized $\mathrm{mAb}$ & $\alpha 4 \beta 7$ & IV & $\begin{array}{l}\text { Phase-III trial against moderately active } \\
\text { ulcerative colitis \& CD has shown } \\
\text { statistically significant } \\
\text { improvement }\end{array}$ \\
\hline Volociximab & Chimeric mAb & $\alpha 5 \beta 1$ & IV & $\begin{array}{l}\text { Phase-I clinical trials in cancers that are } \\
\text { refractory to the standard therapy has been } \\
\text { found to be safe. } \\
\text { Currently undergoing phase-II clinical trial } \\
\text { in combination with erlotinib in patients } \\
\text { with stage-III \& IV non-small cell lung } \\
\text { cancer }\end{array}$ \\
\hline INTEGRILIN/Eptifibatide & $\begin{array}{l}\text { Cyclic hepta-peptide } \\
\text { containing KGD sequence } \\
\text { (gives specificity to } \alpha \operatorname{IIb} \beta 3\end{array}$ & $\alpha \operatorname{IIb} \beta 3$ & IV & Marketed as a drug in coronary thrombosis \\
\hline ATN61 & $\begin{array}{l}\text { Non RGD containing } \\
\text { peptide (Ac-PHSCN-NH2) }\end{array}$ & $\alpha 5 \beta 1$ & IV & $\begin{array}{l}\text { Phase-II clinical trial in combination with } \\
\text { carboplatin in patients with recurrent } \\
\text { intracranial malignant glioma }\end{array}$ \\
\hline $\mathrm{R}-411$ & $\begin{array}{l}\text { LDV peptide mimetic small } \\
\text { molecule }\end{array}$ & $\alpha 4 \beta 1, \alpha 4 \beta 7$ & Oral & $\begin{array}{l}\text { Phase-II clinical trial in the treatment of } \\
\text { asthma has shown encouraging results }\end{array}$ \\
\hline Cilengitide & $\begin{array}{l}\text { head-to-tail cyclized RGD } \\
\text { based antagonist }\end{array}$ & $\alpha v \beta 3$ & IV & $\begin{array}{l}\text { Phase-III clinical trials in combination with } \\
\text { Temozolamide-based radiotherapy for the } \\
\text { treatment of newly diagnosed patients of } \\
\text { GBM with } \mathrm{O}^{6} \text {-methylguanine } \\
\text { methyltransferase (MGMT) promoter } \\
\text { methylation } \\
\text { Phase-II trial in patients with advanced } \\
\text { non-small-cell lung carcinoma showed } \\
\text { comparable efficacy with docetaxel }\end{array}$ \\
\hline Tirofiban (AGGRASTAT) & Small molecule & $\alpha \operatorname{IIb} \beta 3$ & IV & Marketed as a drug in unstable angina \\
\hline Sibrafiban & Small molecule & $\alpha \operatorname{IIb} \beta 3$ & Oral & Withdrawn at phase-III trial \\
\hline Lrfradafiban & Small molecule & $\alpha \operatorname{IIb} \beta 3$ & Oral & Withdrawn at phase-III trial \\
\hline Xemilofiban & Small molecule & $\alpha \operatorname{IIb} \beta 3$ & Oral & Withdrawn at phase-III trial \\
\hline Orbofiban & Small molecule & $\alpha \operatorname{IIb} \beta 3$ & Oral & Withdrawn at phase-III trial \\
\hline AJM-300 & Small molecule & $\alpha 4 \beta 1, \alpha 4 \beta 7$ & Oral & Undergoing phase-II clinical trial for IBD \\
\hline TBS-4746 & Small molecule & $\alpha 4 \beta 1, \alpha 4 \beta 7$ & Oral & $\begin{array}{l}\text { Phase-I clinical trial for the treatment of } \\
\text { asthma and MS }\end{array}$ \\
\hline DW-908e & Small molecule & $\alpha 4 \beta 1, \alpha 4 \beta 7$ & Oral & $\begin{array}{l}\text { Phase-I clinical trial for the treatment of } \\
\text { asthma and MS }\end{array}$ \\
\hline
\end{tabular}


Continued

\begin{tabular}{|c|c|c|c|c|}
\hline Bio-1211 & $\begin{array}{l}\text { LDV peptide mimetic small } \\
\text { molecule }\end{array}$ & $\alpha 4 \beta 1, \alpha 4 \beta 7$ & Oral & $\begin{array}{l}\text { Phase-II clinical trial in the treatment of } \\
\text { asthma has failed }\end{array}$ \\
\hline IVL-745 & Small molecule & $\alpha 4 \beta 1, \alpha 4 \beta 7$ & Oral & $\begin{array}{l}\text { Phase-II clinical trial in the treatment of } \\
\text { asthma has failed }\end{array}$ \\
\hline SB-683699 & Small molecule & $\alpha 4 \beta 1, \alpha 4 \beta 7$ & Oral & $\begin{array}{l}\text { Phase-II clinical trial in the treatment of CD } \\
\text { and MS }\end{array}$ \\
\hline L-000845704 & RGD mimetic small molecule & $\alpha v \beta 3$ & oral & $\begin{array}{l}\text { Phase-I clinical trial in the treatment of } \\
\text { osteoporosis }\end{array}$ \\
\hline SB-273005 & $\begin{array}{l}\text { Small molecule (heterocyclic } \\
\text { RGD mimetics) }\end{array}$ & $\alpha v \beta 3, \alpha v \beta 5$ & oral & $\begin{array}{l}\text { Discontinued after phase-I trial for the } \\
\text { treatment of osteoporosis and arthritis }\end{array}$ \\
\hline L-000845704 & Small molecule & $\alpha v \beta 3$ & Oral & $\begin{array}{l}\text { Phase-I clinical trial shows great efficacy in } \\
\text { increasing lumber spine bone mineral } \\
\text { density (BMD) }\end{array}$ \\
\hline
\end{tabular}

a non-functional variant of RGD.

Not surprisingly, RGD based peptide inhibitors have been a major focus of several drug companies, but have not come without their share of problems. First, linear peptides containing the RGD were found to have a problem with bioavailability. Another problem was selectiviity, as there are multiple integrins that recognize the RGD sequence. Different modifications were done including cyclization \& the use of D-amino acids to improve both bioavailability and selectivity of the RGD peptide inhibitor [27]. $\mathrm{c}(\mathrm{RGDfV})$ is a cyclic peptide with D-form of phenylalanine (f) and was found to have better bioavailability and higher affinity towards $\alpha v \beta 3$ [28,29]. Cilengitide (Figure 3(a)) is a RGD containing cyclic penta peptide $c(R G D f[N M e] 1 V)$ with a much higher affinity towards $\alpha v \beta 3$ than $\alpha v \beta 5$ and has been used in the treatment of different cancers in phase-II clinical trials [30]. Additionally, continuous efforts are being made at the protein engineering level for the design of much more efficient RGD peptide containing inhibitors. One approach that is worth mentioning here is the design of a cystine knot peptide containing the RGD epitope in a solvent exposed fashion. Very recently Kimura et al. reported a cystine knot peptide containing the RGD, called $2.5 \mathrm{~F}$, that could effectively target $\alpha v \beta 3, \alpha v \beta 5 \&$ $\alpha 5 \beta 1$ with very low nanomolar affinity [31]. Such an inhibitor could be useful when blocking of multiple integrins need to be achieved.

Furthermore, there are a large number of low molecular weight (47 - 84 amino acids) RGD-containing polypeptides found in snake venom, called disintegrins, that are available for blocking the function of RGD-containing integrins [27,32]. Rhodostomin is an example of a disintegrin that was found to be effective in the inhibition of bFGF induced angiogenesis in a CAM assay [33]. Disintegrins, due to their larger sizes, cause a significant immune response in our body and are also very susceptible to protease-mediated degradation due to their natural occurrence. Efforts are currently underway for the development of an effective delivery system that would both increase their bioavailability and protect them from an immune response. Swenson et al. have shown that the use of liposomal delivery systems could be very effective for the safe application of disintegrins [34]. They found that contortrostatin, a disintegrin, delivered via liposomes had a much longer half life and reduced immune response.

Inhibitors are also being designed based on non-RGD containing peptide sequences that play some role in integrin recognition. For example, PHSRN is a peptide sequence found in the $9^{\text {th }}$ type-III repeat of fibronectin. This sequence was found to synergistically influence $\alpha 5 \beta 1$ integrin binding to the RGD sequence [35]. ATN161 (Ac-PHSCN-NH2) (Figure 3(b)) is a nonRGD containing peptide inhibitor designed to block interaction of $\alpha 5 \beta 1$ with the synergy site (PHSRN) on fibronectin [29]. This is currently undergoing phase-II clinical trials in patients with solid tumors.

There are also a number of endogenous inhibitors of angiogenesis that are generated due to the degradation of matrix molecules. For example, tumstatin, the NC1 domain of $\alpha 3$ chain of collagen-IV is an endogenous angiogenesis inhibitor. Maeshima et al. showed that tumstatin exerts its anti-angiogenic activity through $\alpha v \beta 3$ but in a RGD independent manner [36]. Thevenard et al. showed that a much shorter peptide, YSNSG (cyclopeptide), derived from the c-terminal domain of tumstatin, containing a very important $\beta$-turn, was highly effective in blocking tumor invasion and tumor angiogenesis [37]. This is an example of a peptide inhibitor that has no relation with RGD.

Finally, the common issue with both $\mathrm{mAb}$ and peptide-based inhibitors is that they need to be parenterally administered, which limits their use as a long term therapy. However, there are some basic differences in the mode of action of these two types of inhibitors. First, binding of the $\mathrm{mAb}$ to its integrin target is usually ireversible due to high affinity, whereas binding of the peptide inhibitor is reversible. Moreover, these two types of inhibitors can be internalized in a different pathway. 


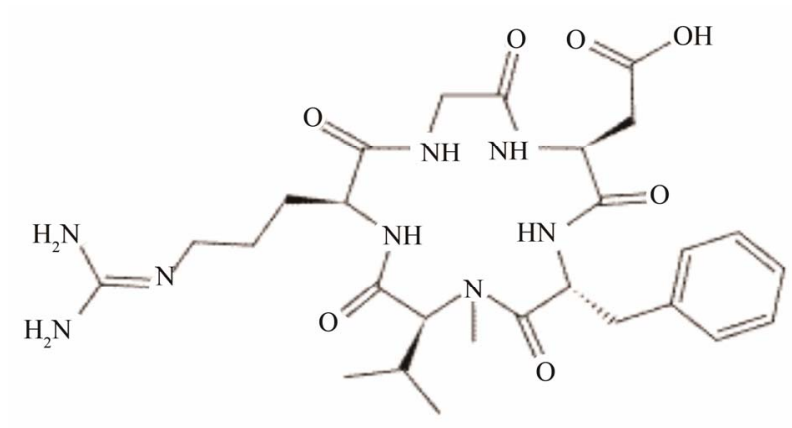

(a)<smiles>CC(=O)N1CCC[C@H]1C(=O)N[C@@H](Cc1c[nH]cn1)C(=O)N[C@@H](CO)C(=O)N[C@@H](CS)C(=O)N[C@@H](CC(N)=O)C(N)=O</smiles>

(b)<smiles>CNc1cccc(CCOc2ccc3c(c2)CN(CC(F)(F)F)C(=O)[C@H](CC(=O)O)C3)n1</smiles>

(c)

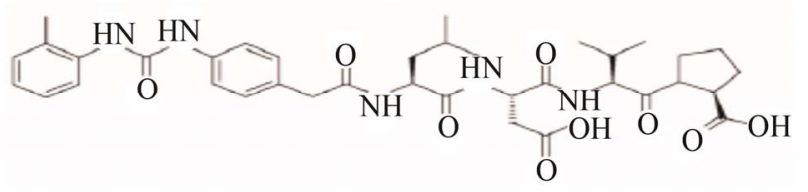

(d)

Figure 3. Molecular structure of different types integrin inhibitor. Panel-a shows cilengitide which is a RGD containing cyclic pentapeptide that acts against $\alpha v \beta 3$ (primarily) and belongs to peptide class of inhibitor of integrins. Panel-b shows the structure of ATN-161 which is a non-RGD containing peptide (Ac-PHSCN-NH2) type of inhibitor that acts against $\alpha 5 \beta 1$. Panel-c shows the structure of SB-273005, a RGD mimetic small molecule type of inhibitor that acts against $\alpha v \beta 3$. Panel-d shows Bio1211 which is a LDV mimetic small molecule type of inhibitor that acts against $\alpha 4$ integrins.

Castel et al. showed that mAb 17E6 underwent endocytosis along with $\alpha v \beta 3$, whereas the cRGD-peptide was endocytosed through an integrin independent fluid-phase pathway and thus didn't cause a change in $\alpha v \beta 3$ expression level at the cell surface [38]. cRGD treated cells were found to readhere to the binding matrix following a washing step but the antibody treated cell didn't.

\section{3) Small Molecule Inhibitor}

This category of inhibitors is mainly organic molecules in nature and thus offers the advantage of oral administration and also better bioavailability. Though these inhibitors are not made of amino acids, a large propor- tion of them are RGD-mimetic. In other words, many of them were designed in a way so that the primary feature of the RGD peptide could be maintained. These RGDmimetic small molecules are mainly made of a centrally constrained structure containing substituents that mimic the arginine and the aspartate residue. It has been found that both the basicity and the length of the arginine mimicking group are essential for proper functionality of the inhibitors [39]. Not only that, the substituent mimicking the carboxyl acid functionality of the aspartate is also critical because this anionic carboxyl group coordinates with the metal cation bound in the MIDAS region of the $\beta$-subunit $[39,40]$. In a review on "Ligands to the integrin receptor $\alpha v \beta 3$ " Duggan \& Hutchison have provided a comprehensive discussion on the design of the various small molecule inhibitors against $\alpha v \beta 3$ [41]. Most of these inhibitors contained one or more rings which provided the central constraint. Various kinds of ring structures were used, including a phenyl group, a 5-member monocyclic aromatic ring, fused bicyclic groups, benzazipine etc. Among the various acidic substituents used at the C-termini of the inhibitors, $\alpha$-sulfonylamino acid, $\alpha$ or $\beta$-substituted propionic acids are a few worth mentioning. Several different kinds of basic groups were used at the N-termini, e.g. guanidine, amidine, benzimidazole etc. Though the basic feature of the arginine has been replaced by a number of different substituents, the carboxylic acid functionality of the aspartate has been found to be the most critical and conserved feature for all of these small molecules inhibitors. But the charged feature of the carboxylic group at neutral $\mathrm{pH}$ has resulted in poor bioavailability. Heckmann et al. reported a novel kind of RGD-mimetic inhibitor by introducing hydroxamic acid at the c-termini [40]. They found that hydroxamic acid could coordinate with the metal ion in the MIDAS region of the $\beta 1$-subunit of the integrin $\alpha 5 \beta 1$. Though there is no RGD-mimetic small molecule inhibitor of integrin is currently available in the market, there are a number of such inhibitors that are currently undergoing clinical trials. One example is L-000845704 which is a RGD-mimetic small molecule inhibitor of $\alpha v \beta 3$. Phase-I clinical trials in patients with osteoporosis have been found to be effective with this molecule $[42,43]$. Another example is SB-273005 which is a heterocyclic RGD-mimetic (Figure 3(c)). This drug has been discontinued after phase-I trial for the treatment of osteoporosis and arthritis [29].

There are also many non-RGD recognizing integrin heterodimers in human cells and those integrins are also playing important roles in many patho-physiological conditions. For example, $\alpha 4$ integrins ( $\alpha 4 \beta 1 \& \alpha 4 \beta 7)$ have been found to play important roles in progression of disease conditions, such as inflammatory bowel disease 
(IBD), asthma etc. These two integrins are not known to recognize their ligand in an RGD-dependent fashion. On the other hand, they can recognize a LDV sequence present in their ligands, such as fibronectin, vascular cell adhesion molecule-1 (VCAM-1), mucosal addressin cell adhesion molecule-1 (MAdCAM-1) etc. [44,45]. There are a number of LDV based small molecule type of inhibitors that have been designed against these two integrins. Bio1211 (Figure 3d), is an urea-based LDV mimicking inhibitor of $\alpha 4$ integrins that have been subjected to phase-II trial of patients with asthma $[16,46]$. It has been found that for many of these LDV-based inhibitors, the critical component is the carboxylic acid moiety, and due to the inherent charged nature of this moiety at physiological $\mathrm{pH}$, modification such as esterification has been performed to improve bioavailability [16]. R-411 is a phenylalanine-based LDV mimicking inhibitor of $\alpha 4$-intgeirns that has been esterified. This molecule has shown encouraging results in early phase-II clinical trials in patients with asthma [47]

\subsubsection{Different Integrin Heterodimers as Drug Target 1) $\alpha v \beta 3 / \alpha v \beta 5$}

In the last few years $\alpha v \beta 3 \& \alpha v \beta 5$ have become major targets for therapeutic intervention in various diseases. The various ligands these two receptors bind to are fibronectin, fibrinogen, vitronectin, thrombospondin, vWbf, osteopontin etc. [48-50]. Though their ligand recognition pattern is promiscuous, both receptors show a very limited expression profile. They are expressed in low amounts in smooth muscle cells, activated macrophages, leukocytes, kidney placenta $[41,48-50]$ etc. They are usually not expressed in epithelial cells. While resting endothelial cells have very little expression, activated endothelial cells show significant upregulation. [13,41, 48]. Osteoclast cells involved in bone resorption and synovial tissue of rheumatoid arthritis patients show high level of $\alpha v \beta 3$ expression [41,48,51]. Several kinds of invasive tumor cells like, prostate cancer, breast cancer, melanoma and glioblastoma cells also show significant level of $\alpha v \beta 3$ expression [48,52,53]. Involvement of these two receptors (especially $\alpha v \beta 3$ ) in various disease conditions, like-cancer, vascular disorders, osteoporosis, rheumatoid arthritis and diabetic neuropathy, have made them a subject of great therapeutic focus. The exact role these two receptors play in these above mentioned disease conditions and how they are targeted for therapeutic intervention will be briefly discussed.

\section{a) Role in Cancer}

Development of cancer and angiogenesis are intrinsically related to each other. Angiogenesis, the process of forming new blood vessels, happens through the activition of endothelial cells of the existing blood vessel. Tumor cells are capable of inducing the de novo forma- tion of blood vessels and thus possess an angiogenic switch [54,55]. New blood vessel formation is an obvious requirement for tumor growth and tumor metastasis and the density of the microvasculature at the tumor site has been found to correlate well with the risk of distant metastasis $[55,56]$ of cancer cells. Tumor cells are capable of secreting cytokines and/or growth factors that in turn activate the endothelial cells of the nearby blood vessel. Endothelial cells are known to express at least 11 different kinds of integrins ( $\alpha 1-6 \beta 1, \alpha 6 \beta 4, \alpha v \beta 1,3,5,8)$ [57,58]. Out of these, $\alpha v \beta 3 \& \alpha v \beta 5$ have been found to be extremely important in mediating tumor angiogenesis. Brooks et al., in their chick chorioallantoic membrane (CAM) assay showed that expression of $\alpha \mathrm{v} \beta 3$ on endothelial cells becomes at least four fold higher compared to the control upon induction of angiogenesis using either basic-fibroblast growth factor (bFGF) or tumor necrosis factor- $\alpha$ (TNF- $\alpha)$ [13]. In this study they also found that use of antagonists such as anti- $\alpha v \beta 3$ antibody (LM-609) blocked the bFGF and TNF- $\alpha$ induced angiogenesis. David Cheresh and his group have proposed existence of another distinct angiogenic pathway. In a study it was found out that P1F6 (anti- $\alpha \mathrm{v} \beta 5$ antibody) could block angiogenesis induced by VEGF, PMA (phorbol-12-myristate-13-acetate) and TGF- $\beta$ (transforming growth factor- $\beta$ ) with minimum effect on bFGFinduced angiogenesis [59]. Thus, based on specific kinds of cytokines released by tumor cells, both $\alpha v \beta 3 \& \alpha v \beta 5$ play a key role in endothelial cell-mediated tumor angiogenesis.

Involvement of $\alpha v \beta 3 \& \alpha v \beta 5$ in tumor angiogenesis has created tremendous enthusiasm among various drug companies for the development of novel integrin based anti-cancer drugs in last few years. Several ligands of both $\alpha v \beta 3 \& \alpha v \beta 5$ (vitronectin, fibronectin, collagen) share a common RGD based recognition sequence. As a result several peptide antagonists based on RGD sequence have been explored in order to block $\alpha v \beta 3$ \& $\alpha v \beta 5$ mediated angiogenesis and thus progression of cancer. David Cheresh and his group found that a cyclic RGD peptide (c(RGDfV)), an antagonist of $\alpha v \beta 3 \& \alpha v \beta 5$, could effectively inhibit angiogenesis induced by both bFGF and VEGF [59]. Tremendous effort has been given by several drug companies in the last few years for designing different RGD-based antagonists with better bioavailability, stability and selectivity over $\alpha v \beta 5$ and other $\alpha$ integrins like $\alpha I I b \beta 3$ etc. Cilengitide (developed by Merck KGaA) is a head-to-tail cyclized RGD based antagonist cyclo(L-arginyl-glycyl-L-aspartyle-D-phenylalanyl-N-methyl-L-valyl) of $\alpha v \beta 3$ that was found to be very effective in blocking the growth of brain tumors, induced by the injection of DAOY (medulloblastoma) and U87 MG (glioblastmoa) cell lines in SCID mice [60]. While cilengitide is known to be a strong inhibitor of 
angiogenesis, Taga et al. showed that cilengitide mediated regression of brain tumor growth is also due to the apoptosis of DAOY and U87 MG cell lines induced by their detachment from vitronectin and tenascin [61]. Cilengitide has been subject to phase-II clinical trials in the treatment of several cancers such as prostate cancer, stage-III/IV myeloma, primary brain tumors in children and glioblastoma multiforme in adults [30,62]. Phase-II clinical trials showed promise in patients with recurrent glioblastoma multiforme (GBM) [63]. Currently, it is being tested in a phase-III clinical trials in combination with temozolamide-based radiotherapy for the treatment of newly diagnosed patients of GBM with $\mathrm{O}^{6}$-methylguanine methyltransferase (MGMT) promoter methylation $[64,65]$. A phase-II trial was conducted to compare the safety and efficacy of cilengitide with docetaxel in the treatment of advanced non-small-cell lung cancer. This study was more of an exploratory type and a small number of patients were enrolled for the trial. With the highest dose of cilengitide progression-free survival and $1 \mathrm{yr}$ survival were found to be comparable with that of observed with docetaxel [66].

Besides RGD-based peptide antagonists, a function blocking antibody against $\alpha v \beta 3$ has also been tried in the treatment of cancer. LM-609 is the mouse-anti-hu- $\alpha v \beta 3$ $\mathrm{mAb}$ that was used by David Cheresh and his group for the inhibition of bFGF induced tumor angiogenesis [13,59]. A humanized version of this $\mathrm{Ab}$ was prepared, known as MED-523 (vitaxin-I) which was further modified (by stepwise maturation of phage expression library) to prepare an antibody called Vitaxin-II/Abegrin/Med522 [67]. Phase-II clinical trial of Abegrin on stage-IV metastatic melanoma, colorectal cancer and androgenindependent-prostate cancer has been completed.

Efforts are also being given for the development of a dual antagonist of $\alpha v \beta 3$ and $\alpha v \beta 5$. Since tumor cells are known to secrete different types of cytokines/growth factors, use of dual antagonists that inhibit two distinct angiogenic pathways (bFGF and VEGF mediated) may have very high therapeutic potential. One example of such a dual inhibitor is CNTO 95, a fully humanized antibody against both $\alpha v \beta 3$ \& $\alpha v \beta 5$ [68]. Currently, CNTO 95 is under phase-II clinical trials in combination with docetaxel and prednisolone for the treatment of metastatic hormone refractory prostate cancer patients [69]. Several other non-peptide small molecule inhibitors of $\alpha v \beta 3$ \& $\alpha v \beta 5$ have been tested for the treatment of cancer. SC-68448 is an orally available small molecule (RGD-mimetic) dual inhibitor of $\alpha v \beta 3$ and $\alpha v \beta 5$. This has been subjected to phase-I clinical trials [48].

\section{b) Role in Vascular Disorder}

Formation of arterial wounds following a coronary intervention such as angioplasty or application of a stent is very common. These processes create damage to the en- dothelial cell lining of the artery and response to such damage determines the success of the intervention. Often times, such arterial wounds cause re-occlusion of the artery following formation of atherosclerotic plaque [50]. This process of re-occlusion of artery is called restenosis. It has been found that migration of vascular smooth muscle cells (SMCs) towards the site of injury plays a key role in development of restenosis [49]. During neointima formation \& restenosis, migration of vascular SMCs towards the site of arterial wounds is found to be critically dependent on the interaction of $\alpha v \beta 3$ receptors (highly expressed on the surface of SMC) with extra cellular matrix component osteopontin which is upregualted during restenosis. [70] Thus $\alpha v \beta 3$-mediated interaction with osteopontin has been proposed to be extremely critical for the migration of SMCs towards the arterial wound and thus formation of restenosis. Several antagonist of $\alpha \mathrm{v} \beta 3$ have been used in order to block the development of restenosis.

Application of the small peptide antagonist GpenGRGDSPCA against $\alpha v \beta 3$, into rabbit carotid artery was found to be very effective in blocking neointima hyperplasia formation [71] following balloon angioplasty. Use of cyclic-RGD based antagonists has been found to be effective in small animal models of restenosis, such as rat or hamster carotid angioplasty models [50]. Another example of the successful use of $\alpha v \beta 3$-antagonist is the small molecule XT199, which was found to cause significant inhibition of restenosis in double artery injury models of hyper-cholesterolemic rabbits [72]. Vitaxin, which is a humanized $\mathrm{mAb}$ against $\alpha v \beta 3$ also reduced neointimal hyperplasia formation in hypercholesterolemic rabbits after balloon angioplasty [73]. Vitaxin is currently being evaluated in early clinical trial for the prevention of restenosis.

\section{c) Role in Osteoporosis}

Osteoporosis, a degenerative disease characterized by continuous loss of bone, has become a major problem, especially among the women who are going through post-menopause. The major features of osteoporosis include loss of bone mass and increased fragility of bone that in turn increases the risk of bone fracture [41,74]. Maintenance of normal bone mass depends on the delicate functional balance between two different kinds of cellsosteoblast and osteoclast. While osteoblasts are involved in bone formation, the main role of osteoclasts is bone resorption [75]. Osteoclast mediated bone resorption requires osteopontin binding to bone surface $[74,76]$. Involvement of integrin $\alpha v \beta 3$ which is highly expressed on mature osteoclast has long been implicated in the attachment of osteoclasts to the bone. Horton et al. showed that use of $23 \mathrm{C} 6$, a mAb against $\alpha v \beta 3$ and a peptide GRGDSP could effectively reduce dentine resorption and osteoclast spreading, respectively [15]. Matrix com- 
ponent such as osteopontin, which is highly upregulated at the osteoclast attachment site, is a known ligand for $\alpha v \beta 3$. McHugh et al. in a study with $\beta 3$-knockouts, showed that the knock-out mice had increased bone mass compared to wild type mice, but the large number of osteoclasts produced in KO-mice was dysfunctional [77]. In another study, Ross et al. could directly inhibit osteoclast attachment to the bone by using LM609, a mAb against $\alpha v \beta 3$ [78].

Such involvement of $\alpha v \beta 3$ in osteoclast mediated bone resorption has prompted several preclinical studies in the prevention of osteoporosis using antagonist of $\alpha \mathrm{v} \beta 3$. SC56631, a peptidomimetic antagonist of $\alpha v \beta 3$, while administered intravenously, showed significant reduction in bone loss in oophorectomized (Ovariectomized) mice. In fact, this compound was also found to reduce the number of mature osteoclast in oophorectomized mice [79]. Several drug companies are putting effort in the efficient design of $\alpha v \beta 3$ antagonist for the treatment of osteoporosis. L-000845704 is a small molecule type orally available $\alpha v \beta 3$ antagonist designed by Merck. It is highly selective against $\alpha \mathrm{IIb} \beta 3$ and $\alpha v \beta 5$. In a phase-I clinical trial it was found to be very effective in increasing lumber spine bone mineral density (BMD) and was also found to be effective in hip regions of patients with low lumber spine and femoral neck BMD [43].

\section{d) Role in Rheumatoid Arthritis}

Rheumatoid arthritis (RA) is a chronic disease that is complicated by multiple patho-physiological responses that include auto-immunity, synovial inflammation \& fibrovascular responses [80,81]. This disease is degenerative in nature and characterized by articular cartilage damage followed by joint destruction. Initiation of the disease (due to injury to the articular cartilage or other reasons) triggers the autoimmune responses in some patients. This is followed by inflammation and proliferation of the synovial lining that gives rise to the formation of pannus (an interdigitating fold of the synovial tissue) $[82,83]$. Formation of pannus plays a major role in the destruction of cartilage and bone. Pannus are invasive in nature and considered as a form of benign tumor. Angiogenesis plays an important role in the survival and proliferation of tumors, and does so for pannus. In fact, angiogenesis is a histopathologic hallmark of RA disease [84,85]. Angiogenic vessels at synovial tissue of RA patients have been found to show high levels of $\alpha v \beta 3$ expression [14]. Interaction of $\alpha v \beta 3$ receptors on the surface of activated endothelial cells with matrix protein such as osteopontin [86] and fibrinogen (highly abundant in synovial tissue of RA patients) has been found to be a key factor in the maintenance of the proliferative feature of the synovial tissue. Continuous neovascularization causes a significant increase in the endothelial bed volume in the synovial tissue and that in turn causes the increased infiltration of inflammatory cells such as activated macrophages and T-cells to the site of synovitis [87]. $\alpha v \beta 3$ is highly expressed in activated macrophages and plays a very important role in the migration of these macrophages to the site of inflammation. Another cell population that is highly abundant in the synovial tissue of RA patients are osteoclasts. Osteoclasts are differentiated macrophages which are involved in the bone destruction of RA patients. Mature osteoclasts show high expression of $\alpha v \beta 3$ and the role of $\alpha v \beta 3$ in osteoclast-mediated bone-resorption has been discussed in the previous section.

The involvement of $\alpha v \beta 3$ in the three key pathological processes (angiogenesis, inflammation \& osteoclast mediated bone resorption) related to RA, has made it a potential drug target in the treatment of this degenerative disease. In a rabbit model of antigen induced arthritis (AIA), Storgard et al. found that intra-articular administration of RGD based cyclic peptide against $\alpha v \beta 3$ decreased synovial angiogenesis, pannus formation and bone erosion [14]. This cyclic peptide was also effective in reducing the severity of pre-existing arthritis. SB273005 is a nonpeptide antagonist of $\alpha v \beta 3$ (and also $\alpha v \beta 5$ ), which was found to be effective in reduction of bone and cartilage erosion in AIA of Lewis rats [88]. A phase-II trial with Vitaxin in the treatment of rheumatoid arthritis has been completed.

\section{e) Role in Ocular Disease}

There are various kinds of ocular diseases, such as retinopathy of prematurity (ROP), age related macular degeneration (AMD) and proliferative diabetic neuropathy (PDR) where retinal neovascularization plays a major role in the disease progression. Like in angiogenesis, happening at other pathological conditions, $\alpha v \beta 3$ plays a major role in retinal neovascularization. Several immunohistochemical studies show high level of $\alpha v \beta 3$ and/or $\alpha v \beta 5$ expression in the newly formed retinal and choroidal blood vessels of patients with above mentioned disease conditions. Pre-existing blood vessels didn't show the presence of $\alpha v \beta 3$ and $\alpha v \beta 5$. Interaction of $\alpha v \beta 3$ with components of the modified extracellular matrix, such as vitronectin, leads to the successful neovascularization of the retinal surface, which eventually extends towards the vitreous region of eye. Neovascularization is followed by formation of fibrovascular scar tissue and finally loss of vision due to vitreous hemorrhage and retinal detachment [89]. The important role of $\alpha v \beta 3$ in ocular angiogenesis has made it a suitable target for therapeutic intervention.

As proof of principle, Hammes et al. showed that subcutaneous injection of cyclic RGDfV peptide (antagonist of $\alpha v \beta 3 \& \alpha v \beta 5$ ) in a mouse model of hypoxia induced proliferative retinopathy prevented retinal neovascularization to a great extent (about 80\%) [90]. 
Cyclic RGD peptide has been successfully tested in the prevention of choroidal neovascularization (CNV) in age-related macular degeneration (AMD) [91]. Another antagonist of $\alpha \mathrm{v}$ integrins, JNJ-26076713 (a small molecule type antagonist) that is orally available, is worth mentioning here. This antagonist was also found to be very effective in the prevention of retinal neovascularization in mice model of ROP [92].

\section{2) $\alpha$ IIb $\beta 3$}

Platelet aggregation has a very important role in the development of arterial thrombosis. Thus anti-platelet therapy holds great promise in the treatment of patients with acute coronary symptoms. Irrespective of the mechanism by which platelet aggregation is induced, the final step of the process involves interaction between integrin $\alpha \operatorname{IIb} \beta 3$ and fibrinogen. $\alpha \operatorname{IIb} \beta 3$ is known to be a platelet integrin receptor as it is almost exclusively found in platelets. Apparently there are about 50,000 $\alpha \operatorname{IIb} \beta 3$ present in each platelet. Platelet activation happens due to binding of different ligands (e.g. ADP, collagen, thrombin) on the membrane bound GPCR and this leads to activation of integrin ("inside-out signaling") mediated through a bunch of intermediate cell signaling molecules. Once $\alpha \operatorname{Ilb} \beta 3$ reaches its high affinity active state it can bind to different ligands. Though $\alpha \operatorname{IIb} \beta 3$ can recognize different ligands (e.g. vitronectin, $v W b f$ ), the main ligand is fibrinogen. Fibrinogen has two RGD motifs in its $\alpha$-chain and thus can bind with two different $\alpha \operatorname{IIb} \beta 3$ simultaneously [6] and acts like a bridge, which helps in the aggregation of platelets. As a result, the $\alpha$ IIb $\beta 3$-fibrinogen interaction has long been targeted for therapeutic intervention.

Different inhibitors of $\alpha \operatorname{IIb} \beta 3$ have been generated by drug companies in the last few years. There are currently three different anti- $\alpha I \mathrm{I} b \beta 3$ drugs that are being marketed. All of them are administered intravenously along with aspirin (anti-platelet agent). The first one is REOPRO/ Abciximab/c7E3, a mouse/human chimeric Fab chimeric Fab portion of the IgG $[93,94]$. The other two are a RGD based inhibitors (INTEGRILIN/ Eptifibatide) and a non-peptide inhibitor of $\alpha \operatorname{IIb} \beta 3$ (AGGRASTAT/Tirofiban). Use of these inhibitors before and during angioplasty in the patients with acute coronary syndrome has been found to significantly decrease the probability of coronary events like myocardial infarction and thrombosis. But intravenous administration of these inhibitors could not prevent the coronary events that happened at later stages [49]. As a result, the development of orally available anti- $\alpha \operatorname{IIb} \beta 3$ drugs for the long-term treatment of acute coronary syndrome has been pursued by several drug companies. Several orally administrable anti- $\alpha \operatorname{IIb} \beta 3$ drugs underwent clinical trials, e.g. xemilofiban, orofiban, sibrafiban, lefradafiban. But unfortunately all of them were withdrawn at phase-III clinical trial (16) due to increased complication and/or ineffectiveness. Though it has remained unanswered as to why orally available anti- $\alpha I \mathrm{Ilb} \beta 3$ inhibitors failed the trials, thoughts are being given in the concomitant use of other anti-platelet drugs (aspirin) and/or anti-coagulant drugs (heparin). While there is no doubt that the antiplatelet therapy targeting at $\alpha \operatorname{IIb} \beta 3$ receptor is probably the most efficient therapeutic intervention in the treatment and prevention of acute coronary syndrome available at this moment, several issues remain that need careful attention and effective strategy planning.

\section{3) $\alpha v \beta 6$}

$\alpha v \beta 6$ is a member of the $\alpha v$ family of integrins. While $\beta$-subunits often heterodimerize with different kinds of $\alpha$-subunits, $\beta 6$ has been found to pair up only with $\alpha \mathrm{v}$ subunit. $\alpha \mathrm{v} \beta 6$ is unique as it is mainly expressed in epithelial cells, though expression can vary from low to almost undetectable in normal adult tissue, depending on the tissue type [22,95]. Under conditions involving tissue remodeling, expression of $\alpha v \beta 6$ goes up, e.g. tissue injury, wound healing and carcinogenesis and fibrosis $[96,97]$.

Several studies have shown that $\alpha v \beta 6$ is expressed in the migratory keratinocytes at the edge of the wound [96]. In humans, expression can be observed at the early stage of wound healing, which increases at the later stage. It has been implicated that $\alpha v \beta 6$ plays a role in the early stage of wound healing by helping in migration of keratinocytes on fibronectin, vitronectin \& tenascin and also by helping in the detachment of the keratinocytes from the basement membrane by activating MMP9 [97-99]. But there are several other studies that suggest $\alpha v \beta 6$ is mainly involved in the later stage of wound healing, primarily mediated by the interaction with tenascin $[100,101]$. Another possibility by which $\alpha v \beta 6$ might play a positive role in wound healing is by activating TGF $\beta$ s. Activated TGF $\beta$ s have been proposed to be involved in wound healing by regulating re-epithelialization, suppression of inflammation \& promoting connective tissue regeneration [102]. While $\alpha v \beta 6$ is considered essential in the process of successful wound healing, expression of the same in several carcinomas is considered an extremely bad marker of prognosis. Though normal epithelial cells show low to almost undetectable amount of $\alpha v \beta 6$ expression, significant upregulation of expression is observed in various kinds of epithelial tumors. Hsiao et al. has shown that not only OSCC, but several other kinds of head \& neck squamous cell carcinoma (HNSCC) show increased expression of $\alpha v \beta 6$, e.g. oropharyngeal, hypopharyngeal, nasop-pharyngeal and laryngeal carcinomas [103]. Several other kinds of epithelial carcinomas such as, carcinoma of colon, breast, stomach, salivary gland, have also been found to be positive for $\alpha v \beta 6$ expression [97]. Addition- 
ally, presence of $\alpha v \beta 6$ plays an active role in tumor invasion [104,105]. Such an important role for $\alpha v \beta 6$ in the survival and progression of epithelial tumors provides a great scope for therapeutic intervention where disruption of the specific interaction of the receptor with the matrix components can be targeted. In a preclinical trial, Xue et al. injected the highly invasive HSC-3 cell line in the floor of the mouth of nude mice in absence and presence of anti- $\alpha v \beta 6$ antibody (10D5). While all the control mice showed tumors, only $40 \%$ of the antibody treated mice showed tumor formation and the size of the tumor was also smaller than that of control mice [106]. Effort has been given in the design of small molecule inhibitors of $\alpha v \beta 6$. Hsiao et al. have very recently reported on the discovery of a RGD-based peptide inhibitor of $\alpha v \beta 6$, from the phage display method. This cyclic peptide CRGDLASLC was found to very effective in recognizing $\alpha v \beta 6$ under pathological condition and was also very selective against other kinds of $\alpha \mathrm{v}$ integrins [103]. This peptide could also effectively block the proliferation of OSCC.

$\alpha v \beta 6$ has also been implicated to play a very important role in the development of fibrotic conditions. Such an effect of $\alpha v \beta 6$ is mainly mediated by virtue of its property of activating Transforming growth factor- $\beta \mathrm{s}$ (TGF $\beta$ s). It has been known that the TGF $\beta$ gene is expressed as a full-length protein that contains a large $\mathrm{N}$-terminal domain and a smaller c-terminal domain. Intracellular proteolysis of this full-length protein causes separation of the N-terminal and c-terminal domains. The N-terminal domain is called latency associated peptide (LAP) and the c-terminal domain is called TGF- $\beta$. A dimer of resulting LAP then forms a non-covalent complex with a dimer of TGF $\beta$. This complex then associates with latent TGF- $\beta$-binding protein (LTBP-1) to form a "large latent complex" [107-110]. There are three different isoforms of TGF $\beta$ s (TGF $\beta-1,2 \& 3$ ) and thus three different kinds of LAPs (LAP $\beta-1,2 \& 3)$. It has been reported in a number of studies that $\alpha v \beta 6$ plays a role in the activation TGF $\beta 1$ [111] and TGF $\beta 3$ [112]. One possible explanation for such activation is that $\alpha \mathrm{v} \beta 6$ binds to LAP $\beta 1 \&$ LAP $\beta 3$ of the corresponding complex in a RGD dependent manner and induces a conformational change that ultimately causes activation of TGF $\beta$ [111]. TGF $\beta$ s play various physiologically important roles, such as cell growth, matrix synthesis, apoptosis etc. In tissues like the lung, large amounts of latent TGF $\beta$ are present. Only a low amount of active TGF $\beta$ is needed for cellular responses. So, TGF $\beta$ activation is highly regulated. TGF $\beta$ s act as suppressor of inflammations, but while expressed at high level, may cause accumulation of matrix components leading to fibrosis. It has also been found that under certain fibrotic conditions (pulmonary or biliary), $\alpha v \beta 6$ expression goes up [113,114]. Huang et al. found that $\alpha v \beta 6$ knock-out mice developed skin and lung inflammation [115] after challenged with some environmental insult. But later, Munger at al. showed that the same mice challenged with bleomycin (classical model for induction of lung fibrosis) didn't develop any fibrosis where as wild type did [111]. These studies indicated that $\alpha v \beta 6$-mediated activation of TGF $\beta$ plays a critical role in the development of fibrosis. Thus blocking of TGF $\beta$ function or $\alpha v \beta 6$ mediated activation of TGF $\beta$ may become useful in the successful control of fibrosis. Since TGF $\beta$ plays various important physiological roles, targeting TGF $\beta-\alpha v \beta 6$ interaction is probably more effective. Antibodies that block such interactions and thus activation of TGF $\beta$ s have been a recent area of interest. Weinreb et al. reported development of two monoclonal antibodies against $\alpha v \beta 6$ (6.8G6, a ligand mimetic $\mathrm{mAb}$ and $6.3 \mathrm{G} 9$, a non-ligand mimetic $\mathrm{mAb}$ ) that disrupted the interaction of this receptor with its ligand like LAP of TGF $\beta$ and fibronectin. The antibody 6.3G9 has been successfully used in the prevention of biliary obstruction-induced fibrosis [114]. In another study 6.3G9 was found to be also useful in the prevention of radiation-induced lung fibrosis of mice [116]. Though targeting the interaction between $\alpha v \beta 6 \&$ TGF $\beta$ holds great promise in the efficient prevention of fibrotic conditions, one issue that needs attention is the inflammatory response that may result from the absence of TGF $\beta$ s. A proper optimization will probably be needed in terms of both dose and duration so that effective prevention of fibrotic conditions can be achieved before the onset of inflammation. Though study with mice is so far encouraging, a successful human trial is still awaiting.

\section{4) $\alpha 4$ integrins $(\alpha 4 \beta 7 \& \alpha 4 \beta 1)$ as drug target}

The $\alpha 4$-subunit is known to pair up with two different types of $\beta$-subunits $\beta 7 \& \beta 1 . \alpha 4 \beta 7$, known as lymphocyte peyer's patch adhesion molecule-1 (LPAM-1) and $\alpha 4 \beta 1$, known as very late antigen (VLA-4) are mainly associated with immune cell leukocytes and play important role in leukocyte adhesion, migration and extravasation. Both $\alpha 4 \beta 7 \& \alpha 4 \beta 1$ are constitutively expressed on the surface of lymphocytes, eosinophils, basophils, macrophages etc. None of these integrins are found to be expressed in human neutrophils, [16,117,118]. Leukocyte extravasation across the vascular endothelial layer involves interaction of $\alpha 4$ integrins on the lymphocyte surface, with their specific ligands expressed on the endothelial cell surface. The main ligand of $\alpha 4 \beta 1$ integrin on the endothelial surface is Vascular Cell Adhesion Molecule-1 (VCAM1), whereas for $\alpha 4 \beta 7$ the main ligand is Mucosal Addressin Cell Adhesion Molecule-1 (MadCAM-1), though $\alpha 4 \beta 7$ is also known to recognize VCAM-1 too $[119,120]$. Both of these integrins are also known to recognize extra cellular component fibronectin. Due to their involvement in leukocyte functionality, the- 
se two $\alpha 4$ integrins have been implicated in various autoimmune disease conditions. $\alpha 4 \beta 7$ has been implicated to be mainly involved in the inflammatory bowel diseases (IBD) such as Crohn's disease (CD) \& ulcerative colitis (UC) where as $\alpha 4 \beta 1$ has been found to involved in diseases like asthma, rheumatoid arthritis, multiple sclerosis (MS) etc. [16,118,121].

Maintaining tolerance to normal bacterial flora and providing defense against continuous exposure to pathogen is a daunting task for the immune system in the gastrointestinal tract. Under normal homeostasis conditions, naïve lymphocytes continuously circulate between blood and mesenteric lymph node (MLN), gut associated lymphoid tissue (GALT) such as Peyer's patches (PP), gut epithelium, lamina propria (LP) etc. in the search for antigens. Initial stage of lymphocyte rolling along the endothelial surface involves interaction of $\alpha 4 \beta 7$ and/or L-selectin (expressed on the surface of lymphocyte), with MAdCAM and peripheral lymph node addressin (PNAd), respectively, expressed on the high endothelial venule (HEV) of MLN, PP and LP etc. This is followed by chemokines (CCL19 \& CCL21) binding to the Gprotein coupled chemokine receptor (CCR9) on the surface of lymphocyte, which in turn causes high affinity maturation of $\alpha 4 \beta 7$ via "inside out" signaling. $\alpha 4 \beta 7$ at the high affinity stage interacts very tightly with MAdCAM leading to firm adhesion followed by transmigration in to the lymphoid tissue. When naïve lymphocytes encounter antigen presenting dendritic cells (DC) in the lymphoid tissue, they get activated and differentiate into effector and memory cells which lead to significant upregulation of $\alpha 4 \beta 7$ on the surface [122-125]. In inflammatory bowel disease, leukocyte recruitment to the site of inflammation becomes completely dysregulated. $\alpha 4 \beta 7$-mediated continuous trafficking of lymphocytes to the intestinal mucosa worsen the chronic nature of the disease condition. Beside directly helping trafficking of lymphocytes, $\alpha 4 \beta 7$ also plays an important role in the lymphocyte proliferation and inflammatory cytokine production [126]. Such an important role of $\alpha 4 \beta 7$ in IBD has turned it into an important drug target.

Multiple sclerosis (MS) is an inflammatory disease of the central nervous system (CNS) characterized by the pathological demyelination along with sparing of axon [127] which leads to impaired nerve conduction and eventually paralysis. Infiltration of circulating leukocytes in to the CNS has been found to be involved in mediating this auto-immune inflammatory disease. Under normal conditions, leukocyte infiltration across the blood-brainbarrier (BBB) is strictly controlled. But in MS and its experimental model, Experimental Autoimmune Encephalomyelitis (EAE), such control is compromised. Uncontrolled trafficking of lymphocyte (mainly T-cells) to the CNS has been unarguably considered to be the major effector of the chronic feature of MS and EAE. The basic mechanism by which T-cell transmigrate through the endothelial barrier is very similar to that found in IBD. The only difference is that the $\alpha 4 \beta 1$ VCAM-1 interaction remains at the heart of leukocyte-endothelial interaction instead of $\alpha 4 \beta 7$-MadCAM interaction. The role of $\alpha 4 \beta 1$ in EAE has been confirmed by the use of mAb against $\alpha 4$ integrin. Yendock et al. showed that in EAE (the experimental model of MS), use of $\mathrm{mAb}$ against $\alpha 4$ integrin could effectively block leukocyte accumulation in the CNS and also lead to the development of autoimmune encephalomyelitis [128].

Uncontrolled inflammation is also a characteristic feature of rheumatoid arthritis and involvement of T-lymphocyte has been implicated in the inflammation of rheumatoid synovium [129]. Maintenance of the chronic inflammatory condition requires the transmigration of $\mathrm{T}$ lymphocyte to synovial tissue across the endothelial vessel [130]. Though both $\alpha 4 \beta 1 \& \alpha 4 \beta 7$ are also expressed on rheumatoid arthritis associated T-lymphocyte, the $\alpha 4 \beta 1$-VCAM-1 interaction plays the major role in the inflammatory responses associated with arthritis [131]. Expression of VCAM-1 on the endothelial surface and $\alpha 4 \beta 1$ on the T-lymphocyte surface has also been found to be up-regulated in rheumatoid arthritis [130,132].

The role of $\alpha 4 \beta 1$ in asthma, on the other hand, is eosinophil mediated. Eosinophils play a central role in the various pathological symptoms of asthma, such as airway obstruction, edema, secretion of mucous and increased bronchial airway hyper-responsiveness (BHR) [133]. Though mast cells act at the initial phase of asthmatic response by secreting immediate effectors of inflammation such as histamines, prostaglandin etc., eosinophils mediates the late phase (allergic) response (LPR) of asthma and gives it a chronic feature [134]. The mechanism by which eosinophils mediate the perpetual nature of the inflammatory conditions in asthma is complicated by the involvement of multiple factors including inflammatory cytokines, cell adhesion molecules and interaction of eosinophil with other cellular components etc. $\alpha 4 \beta 1$, which is upregulated on eosinophil surface during inflammation, plays a major role in maintaining the inflammatory feature of asthma. The process by which eosinophils pass through the endothelial lining to the interstitium of the lung requires interaction of $\alpha 4 \beta 1$ (on the eosinophil cell surface) with VCAM-1 expressed on the endothelial cells. Once in the interstitium, interaction of $\alpha 4 \beta 1$ with fibronectin plays an important role in the migration of eosinophils through the interstitium $[133,135,136]$. Due to the pivotal role of $\alpha 4 \beta 1$ in eosinophil-mediated asthmatic response, antibody and peptide antagonists against $\alpha 4 \beta 1$ have been tried in the treatment of asthmatic conditions.

Direct involvement of $\alpha 4$ integrin in these above- 
mentioned auto-immune inflammatory diseases has created significant interest in the development of antagonist targeted against $\alpha 4$ integrins. The antagonist that is worth mentioning at the very first is Natalizumab (Tysabri), a humanized monoclonal antibody that works against $\alpha 4 \beta 1$ $\& \alpha 4 \beta 7$ integrins. Successful results at the first year following phase-III trial of Natalizumab in patients with MS, led to the FDA approval of the drug for clinical application [127,137]. But at the second year following phase-III trial, two patients were reported to have progressive multifocal leukoencepthalopathy (PML), a demyelination disease of brain caused by human polyomavirus JC [127,137-139]. Another patient was also reported to have PML from the clinical trial of Natalizumab in Crohn's disease [140]. As a result, Natalizumab was withdrawn from the market in 2004, but reintroduced to the market in 2006 [16,137] under the condition of being applied to patients that are not exposed to any other immune-suppressive agents. Currently it is being clinically applied for the treatment of MS and CD $[121,137]$ with a minor risk of occurrence of PML. As of December, 2011, 207 cases of PML have been reported in 95,300 patients that have received Natalizumab $[141,142]$. A recently reported concern with Natlizumab treatment of MS is a case of development of primary CNS lymphoma (PCNSL) in a 40-year old man who received 21 doses of the drug [143]. A direct relation between Natalizumab treatment and development of PCNSL could not be established, given the number of patients being treated for MS with Natalizumab. The probability of occurrence of PCNSL in people of less than 40 years age is less than 0.3 in 100,000 . A phase-II trial was also started with Natalizumab for the treatment of moderate to severe rheumatoid arthritis in patients receiving concomitant treatment with methotrexate. But the trial has been terminated following the reporting of three cases of PML. A single caseof T-cell lymphoma has also been reported on a patient receiving Natalizumab for the treatment of MS [142].

More prominent involvement of $\alpha 4 \beta 7$ in the IBD has led to the development of antibody that specifically works against $\alpha 4 \beta 7$. Vedolizumab (MLN-002) is a humanized mAb that targets specifically $\alpha 4 \beta 7$ and specifically blocks interaction of $\alpha 4 \beta 7$ with MAdCAM and fibronectin and doesn't induce systemic immunosuppression like natalizumab. A phase-II trial involving this $\mathrm{mAb}$ against moderately active ulcerative colitis \& CD was completed with statistically favorable results $[16$, $118,121,144]$. Phase-III clinical trial conducted in patients with moderately active ulcerative colitis \& CD, who have failed to respond to at least one conventional therapy, showed statistically significant improvement over placebo in terms of meeting the primary end point. The inherent difficulty of antibody therapy due to intra- venous administration has led the pharmaceutical companies in the design of small molecular antagonist against $\alpha 4$ integrins. Davenport et al. in a review on $\alpha 4$-intgerin antagonism has provided a comprehensive discussion of the different small molecule antagonists that have been subject to clinical trial [16]. Bio-1211 \& IVL-745 are two small molecule antagonists (urea based) of both $\alpha 4 \beta 1 \& \alpha 4 \beta 7$ that failed phase-II clinical trial for the treatment of asthma due to poor bioavailability $[16,145,146]$. There are two other urea based small molecule antagonists, TBS-4746 \& DW-908e, that have been subject to phase-I clinical trial for the treatment of asthma and MS [16]. R-411 \& AJM-300 are two different phenylalanine-based small molecule antagonists of $\alpha 4$ integrins. R-411 has showed encouraging result at the early phase of phase-II clinical trials for Asthma [47] and AJM-300 is currently being evaluated at the phase-II clinical trial for IBD [47]. Another phenylalanine based antagonist is SB-683699 that is currently being evaluated at phase-II clinical level for the treatment of both CD and MS [16].

\section{5) $\alpha 5 \beta 1$}

Though the $\beta 1$-subunit pairs up with eleven different $\alpha$-subunits forming eleven different types of integrins, the $\alpha 5$-subunit pairs up with the $\beta 1$-subunit only and thus forms $\alpha 5 \beta 1[24,147]$. $\alpha 5 \beta 1$ shares a lot of similarity in its functionality with $\alpha v \beta 3$. Like $\alpha v \beta 3, \alpha 5 \beta 1$ is also involved in angiogenesis associated with tumor development. While expression of $\alpha 5 \beta 1$ is very minimal in quiescent endothelial cells, activated endothelial cells show significant increase in the expression of $\alpha 5 \beta 1$. Kim et al. using CAM model of angiogenesis, showed that $\alpha 5 \beta 1$ expression was highly upregulated in angiogenesis induced by growth factors such as bFGF \& TNF- $\alpha$ [17]. They found that $\alpha 5 \beta 1$ expression was not upregulated under the influence of VEGF. This indicated that the $\alpha 5 \beta 1$-induced angiogenesis followed the similar path as with $\alpha v \beta 3$. They also showed the presence of $\alpha 5 \beta 1$ expression in human colon \& breast carcinoma tissue, whereas expression was not detected in normal human colon \& breast tissue. Magnussen et al. later confirmed by confocal microscopy the overexpression of $\alpha 5 \beta 1$ on the luminal surface of the endothelial cells of the tumor vessel in rats [148]. Though $\alpha 5 \beta 1$ expression is very low in quiescent endothelial cells, there are some exceptions where high expression is observed under resting conditions, e.g. high endothelial venules (HEVs) of lymph nodes and normal hepatic sinusoids [149]. $\alpha 5 \beta 1$-mediated angiogenesis required the interaction of this receptor with fibronectin $[35,147]$. Inhibitors that could block interaction between $\alpha 5 \beta 1$ and $\mathrm{FN}$ were found to effectively prevent $\mathrm{bFGF}$ and TNF- $\alpha$ induced angiogenesis in CAM models. Interaction of $\alpha 5 \beta 1$ with FN is RGD dependent and the RGD sequence is present at the $10^{\text {th }}$ 
type-III FN repeat. Another peptide sequence (PHSRN) was discovered to be present at the $9^{\text {th }}$ type-III repeat of FN, playing a synergistic role in RGD dependent interaction with $\alpha 5 \beta 1$ [35].

Increased expression of $\alpha 5 \beta 1$ has been associated with various kinds of cancer cells, such as astrocytoma, glioblastoma, colon carcinoma etc. [150,151]. Expression of $\alpha 5 \beta 1$ on these types of tumor cells plays very important roles in the progression of the cancer. Maglott et al. showed that use of SJ749, a highly selective non peptide antagonist of $\alpha 5 \beta 1$ [152], significantly reduced proliferation and adhesion of two different astrocytoma cell line A172 \& U87 to FN [153]. Gong et al. found that highly invasive group I colon carcinoma cell expressed high level of $\alpha 5 \beta 1$ expression compared to weakly tumorigenic group III colon carcinoma [151]. This finding clearly indicated the possible role of $\alpha 5 \beta 1$ in the malignnant progression of colon carcinoma cells.

Due to its important role in angiogenesis, $\alpha 5 \beta 1$ has been implicated in various pathological conditions beside cancer, such as choroidal neovascularization and proliferative vitreoretinopathy. Umeda et al. established the essential involvement of $\alpha 5 \beta 1$ in choroidal neovascularization. In a laser-induced choroidal neovascularization model of mice, they showed overexpression of $\alpha 5$ integrin in vascular cells. They also showed that use of selective inhibitor of $\alpha 5 \beta 1$, JSM6427, effectively suppressed the choroidal neovascularization [154]. Zahn et $a l$. on the other hand showed the essential role of $\alpha 5 \beta 1$ in the development of proliferative vetreoretinopathy (PVR). PVR is a process of abnormal wound healing and its common pathological symptoms include ocular inflammation, cellular proliferation and retinal scarring [155]. It has been found that migration and adhesion of retinal pigment epithelial (RPE) cells plays an important role in the formation of epiretinal membrane (EPR) in PVR $[156,157]$. Jin et al. showed that the interaction between $\alpha 5 \beta 1$ expressed on the surface of RPE and FN of the provisional matrix is essential for the formation of EPR [157]. Jin et al. also showed that in a rabbit model of retinal detachment, intravitreal injection of JSM6427 efficiently reduced the length and number of subretinal scars.

Besides its important role in angiogenesis and vasculogenesis, $\alpha 5 \beta 1$ is also involved in formation of new lymphatics from the existing lymphatic vessels (lymphangiogenesis). Lymphatic vessels play important roles in normal tissue homeostasis and also in immune surveillance, inflammation and metastatic progression of cancer [158-160]. Several growth factors such as VEGF$\mathrm{C} \&$ VEGF-D induce lymphangiogenesis via VEGFreceptor-3 (VEGFR-3) and there is evidence of clear involvement of $\alpha 5 \beta 1$ in such VEGFR-3 mediated induction of lymphangiogenesis $[158,161]$. Dietrich et al. showed that inhibition of $\alpha 5 \beta 1$ by small molecule inhibitor (JSM6427) could effectively inhibit lymphangiogenesis in a mouse model of corneal inflammation [162].

Among all the inhibitors of $\alpha 5 \beta 1$, perhaps the most important one is volociximab, a monoclonal antibody that was designed to block interaction between $\alpha 5 \beta 1$ and FN. Phase-I clinical trials with volociximab in patients with various kinds of cancer that are refractory to standard therapy (colorectal, breast, melanoma, renal cell carcinoma etc.) have been found to be safe [163]. A phase-II clinical trial with volociximab in combination with erlotinib is currently underway in patients with stage-III \& IV non-small cell lung cancer. ATN-161 is another inhibitor of $\alpha 5 \beta 1$. It is a peptide inhibitor (AcPHSCN-NH2) that targets the synergy site (PHSRN) of $\alpha 5 \beta 1-\mathrm{FN}$ interaction. Livant et al. showed that use of this antagonist could effectively reduce tumor growth and neovascularization in rats injected with MLL rat prostate cancer cells [164]. A phase-I/II clinical trial with ATN161 in combination with carboplatin is currently underway in patients with recurrent intracranial malignnant glioma.

\subsubsection{Major Concerns in Direct Targeting of Integrin}

While integrins have created tremendous interest among the pharmaceutical companies as therapeutic targets, there are several issues that are the subject of major concern. A comprehensive discussion on some of these concerns related to the possible use of $\alpha v \beta 3 \& \alpha \mathrm{v} \beta 5$ as therapeutic target in tumor angiogenesis have been made by Gordon Tucker in his review on "inhibitors of integrins" [58]. While a detail discussion of all the concerns related to targeting integrins are out of the scope of this present review, some major points will be briefly touched upon.

\section{1) Targeting Proper Integrin}

The first thing that must be considered and has been notoriously challenging so far, is to target the proper integrins involved in a specific disease condition. There are about 11 different types of integrins that are expressed in endothelial cells $(\alpha 1-6 \beta 1, \alpha v \beta 1,3,5,8$ and $\alpha 643)$ $[57,165]$. Out of these, $\alpha v \beta 3 \& \alpha v \beta 5$ have been considered to be the most potential target for therapy against tumor angiogenesis [166]. Even then, significant doubt exists as to the universal importance of these two integrins in different kinds of tumors and in tumors at different sites. Enhanced pathological angiogenesis have been observed in the subcutaneous graft of lung and colon carcinoma in mice lacking $\beta 3$ integrin [167]. This raised a question of possible involvement of other integrins like $\alpha 1 \beta 1$ and $\alpha 2 \beta 1$, rather than $\alpha v \beta 3$, in the angiogenesis of tumors located in the skin [58,168]. $\alpha 5 \beta 1$ has recently gained tremendous importance for its role in angiogenesis \& vasculogenesis. In fact, $\alpha 5$ null mutant is 
embryonic lethal [169], indicating a much more essential role of $\alpha 5 \beta 1$ in angiogenesis and vasculogenesis. Cilengitide, (a cyclic RGD based antagonist of $\alpha v \beta 3$ ) when applied to glioma implanted under the skin of mice, showed no effect, whereas while applied to the same tumor implanted in the brain showed effective response in low doses [60]. This indicates that the kind of integrin responsible for pathological angiogenesis can be different from one tissue type to another. This can be further supported by the fact that the genetic ablation of certain kinds of integrin only affects developmental vascularization of a specific tissue or organ. For example, $\alpha v-$ knockout mice shows defects only with developmental angiogenesis of brain and intestine [170]. Thus effective targeting of integrin for a specific disease condition also requires a wise consideration for tissue specificity.

Another point that needs to be considered while targeting specific integrins is the inherent redundancy of integrin function. A specific disease condition can be influenced by multiple integrins. Thus inhibiting one can only cause partial reversal of the diseased state. Tumor angiogenesis in several kinds of tumors are modulated by $\alpha v \beta 3 \& \alpha v \beta 5$ both. Thus inhibiting only $\alpha v \beta 3$ can only be partially beneficial. Thus drugs that can target both are being explored. Similarly, both $\alpha 4 \beta 1 \& \alpha 4 \beta 7$ play important role in rheumatoid arthritis besides $\alpha v \beta 3$. Thus, use of inhibitors against either $\alpha v \beta 3$ or the $\alpha 4$ integrins can only achieve partial reversal of the disease condition.

2) Design of Drug-Issue of Selectivity and Specificity

A significant number of integrin antagonists have been designed based on the RGD sequence. Some of these are peptides that consist of the RGD sequence and some of these are small molecules that mimic RGD structure. There are about eight integrins ( $\alpha v \beta 1,3,5,6,8, \alpha \operatorname{IIb} \beta 3$, $\alpha 5 \beta 1, \alpha 5 \beta 8)$ that recognize RGD sequence present among various matrix molecules. Thus design of a drug that can recognize the RGD sequence comes with a risk of reduced selectivity. Many RGD based inhibitors against $\alpha v \beta 3$ are commonly found to recognize $\alpha v \beta 5$ too. While this can be favorably used in the treatment of angiogenesis where both $\alpha v \beta 3$ and $\alpha v \beta 5$ are involved, characterization of specificity towards other RGD-recognizing integrins is extremely important. Natalizumab is a common inhibitor of both $\alpha 4$ integrins $(\alpha 4 \beta 1 \& \alpha 4 \beta 7)$ [127]. Since these two $\alpha 4$ integrins are expressed in various kinds of immune cells, use of natalizumab often causes systemic immune-suppression. As a result, use of antagonist specifically targeted to one type of $\alpha 4$ integrin has been tried. Vedolizumab is a $\alpha 4 \beta 7$ specific antagonist that has been tried in ulcerative colitis and CDs [144]. While this minimizes the risk of immune-suppression, use of this inhibitor where both $\alpha 4$ integrins are involved would bring only partial benefit.
How integrin antagonists are influencing the activation state is another concern [58]. Integrins can exist in different activation states each featuring a specific conformation. Binding of antagonist can affect the activation state of the integrin, which in turn can affect the specific signaling events that the concerned integrin participates in. A specific cyclic-RGD based antagonist of $\alpha v \beta 3$ was found to be an agonist at low doses and an antagonist at high doses [171]. It was proposed that such antagonist binding caused activation of $\alpha v \beta 3$. At low dose, the quicker release of the antagonist left the integrin in an activated state resulting in agonism of activity, whereas at high saturating dose of antagonist the integrin was restricted from its ligand binding activity. Reynolds et al. recently reported another study where they showed that use of RGD mimetic inhibitors of $\alpha v \beta 3 \& \alpha v \beta 5$ at low nanomolar concentration, caused increased tumor growth due to increase in VEGF mediated angiogenesis [172]. These findings posed some concerns towards the therapeutic prospects of RGD-based inhibitors of $\alpha v \beta 3 / \alpha v \beta 5$ like cilengitide which has shown promise in phase-II clinical trials for the treatment of patients with glioblastoma. This was followed by a publication of a thoughtful discussion by Weis et al., where they commented on the safety of the use of cilengitide in clinical trials and also pointed out the technical differences between the cilengitide clinical trial and the way the experiments were conducted by Reynolds et al. In the same year, Weller et al. published a letter to the editor in response to the findings of Reynolds et al., where they provided logical arguments in support of the efficacy and safety of cilengitide use. While such scientific discussion will continue enlightening us, the fact that an antagonist can act as an agonist under certain condition, should be given serious consideration. We must not forget that out of all the different types of cancers tried with cilengitide, only a subpopulation of glioblastoma showed significant improvement to cilengitide treatment. This probably points to the fact that how integrin inhibitors work is much more complicated than was perceived.

Moreover, it's not clearly known for most of the antagonists whether they recognize their target integrin at activated state or resting state. An antagonist that stabilizes integrin at its resting stage or that blocks ligand recognition by binding only to the activated state can exhibit a completely different perspective both in terms of use and effect.

\section{3) Long Term Therapy}

Significant emphasis is being given by the drug companies for the design of orally available small molecule integrin antagonists. Drugs that are of monoclonal antibody or peptide in nature are only available in parenteral formulation, which makes them very unsuitable for longterm use. So the current emphasis has been on the design 
of small molecule inhibitors that could be orally applied for long term therapy. But, is long-term therapy with integrin inhibitors going to be effective or safe? There are a number of integrins that are involved in pathological angiogenesis, besides $\alpha v \beta 3 \& \alpha v \beta 5$. $\alpha v \beta 3$ has been considered extremely important in pathological angiogenesis and several antagonists have been designed to block $\alpha v \beta 3$ mediated uncontrolled angiogenesis that happens in pathological conditions such as tumor progression, diabetic retinopathy etc. But Reynolds et al. [167] found that genetic ablation of $\beta 3$ and/or $\beta 5$ didn't block pathological angiogenesis. In fact, they found that absence of these integrins actually enhanced angiogenesis \& tumor growth. This finding caused the scientific community to revisit the role of $\alpha v \beta 3 \& \alpha v \beta 5$ in angiogenesis. In that article, Reynolds et al. and in a following commentary by Peter Carmeliet [173], comprehensive discussions have been put forth in order to explain the mechanistic discrepancy between the genetic study and antagonist effect. One of the explanations for such discrepancy was the possible involvement of another angiogenesis pathways in $\beta 3 \& \beta 5$ knock out mice. If that is true, then a concern remains on what would be the effect of long-term inhibition $\alpha v \beta 3$ or $\alpha v \beta 5$. Would long-term inhibition invoke alternate angiogenesis pathway? So far, short-term inhibition of these integrins in clinical trial has not showed up any alternate compensatory pathway, but a long-term trial has yet to be carried out. Not only this, the safety issue associated with the long-term use of integrin inhibitors is also a concern. For example, long-term inhibition of $\alpha 4 \beta 1$ will cause continuous systemic immune-suppression and understanding the effect of such suppression will require careful monitoring.

\subsection{Diagnosis \& Imaging}

Imaging of pathological situations such as tumor site and tumor related angiogenesis, atherosclerosis etc. are of extreme clinical importance both in terms of diagnosis and disease monitoring. Not only for diagnosis, imaging of pathological conditions following application of drugs is also important for the successful evaluation of the effect of the drug. In last few years, biomarkers have gained tremendous importance as a target of imaging. Biomarkers related to imaging refer to any kind of parameters (biochemical, anatomical, molecular etc.) that can reflect the status of a disease condition [174]. Presently biomarkers are being extensively studied for possible consideration as "surrogate" end points in preclinical and clinical studies [174]. Successful application of biomarkers as "surrogate" end points will not only overcome some of the difficulties associated with traditional end points (morbidity, mortality) but will also expedite the process of drug approval. Moreover, biomarker im- aging is being applied for drug discovery and development, too. Performing such imaging in a non-invasive fashion makes the process much easier for both the patient and the clinician. Presently, there are a number of non-invasive imaging processes available. The few that are mostly used are positron emission tomography (PET), single photon emission tomography (SPECT), magnetic resonance imaging (MRI) and computed tomography (CT). There are a few other processes, like ultra sound (US) and optical imaging (OI) that are used to a relatively lesser extent $[175,176]$. A useful overview on all these different types of imaging techniques is available in the review by Rudin et al. [177]. Though extremely useful, these techniques have some inherent problems. They can be difficult to standardize, and thus technically challenging and sometimes the interpretation of the observation is difficult, too $[175,178]$. As a result, significant emphasis is being given towards using these techniques for molecular imaging where biomolecules that are specific to a pathological condition, such as cancer, are being targeted.

Angiogenesis has also been found to be intrinsically related to the prospect of tumor progression. Tumor development/progression and angiogenesis share a positive correlation. Angiogenic vessels are characterized by the high expression of integrin $\alpha v \beta 3 \& \alpha \mathrm{v} \beta 5$ on the surface of their activated endothelial lining [59,179]. Such high expression is not observed in the quiescent endothelial cells. Thus $\alpha v \beta 3$ \& $\alpha v \beta 5$ can serve as useful molecular biomarker for evaluating angiogenesis and tumor progression. In fact, $\alpha v \beta 3$ is the most extensively studied biomarker that has been used for molecular imaging of various conditions that involve angiogenesis. Imaging of $\alpha v \beta 3$ as biomarker, has been applied for other conditions too, such as early atherosclerotic plaque and osteolytic bone metastasis $[178,180]$. In this section, a brief discussion will be carried out on the different targeting strategies that are available for imaging mainly av $\beta 3$ and some other integrins.

Molecular imaging of biomarkers relies on targeted use of ligands through traditional imaging techniques like PET, MRI etc. When $\alpha v \beta 3$ is the target for molecular imaging, the most common ligand that catches our attention are RGD-based peptides. RGD-based peptides are being extensively studied for their possible use as radiopharmaceutical in PET or SPECT imaging. RGDbased ligands (mainly cyclo-peptides) are being tagged with radio-halogen such as $\left[{ }^{18} \mathrm{~F}\right],\left[{ }^{125} \mathrm{I}\right]$ and with radio-isotopes of metals, such as $\left[{ }^{64} \mathrm{Cu}\right],\left[{ }^{111} \mathrm{In}\right]$. Significant emphasis is currently being given for the improvement of pharmacokinetic parameters of these radiotracers. Modifications such as incorporation of a sugar moiety or PEGylation of the RGD peptide have been found to significantly improve both the tumor uptake and pharmacoki- 
netic property of the radiotracers. Chen et al. have reported that incorporation of PEG moiety with the radiotracer $\left[{ }^{64} \mathrm{Cu}\right]-\mathrm{c}(\mathrm{RGDyK})$-DOTA significantly improved the pharmacokinetic property [181] of the original radiotracer. Multimeric RGD peptides are also being studied for molecular imaging of $\alpha v \beta 3$. These types of peptides have been found to be very effective in tumor uptake of the tracer as they can take the advantage of multivalent feature of integrin-ligand interaction naturally found in body. One example of such radiotracer is a radiometallated tetrameric RGD peptide, $\left[{ }^{64} \mathrm{Cu}\right]-\mathrm{DOTAE}-[\mathrm{E}[\mathrm{c}$ (RGDfK)]2]2, which has been used in the PET imaging of U87MG glioma xenograft in nude mice [182]. This radiotracer was found have much better receptor binding affinity and pharmacokinetic properties compared to its monomeric or dimeric analogues. Monoclonal antibodies specifically targeted against integrins are also under trial for molecular imaging, besides RGD peptides. MEDI522 is a fully humanized $\mathrm{mAb}$, targeted against $\alpha \mathrm{v} \beta 3$, currently undergoing clinical trial for the treatment of cancer. A radiotracer, based on this antibody, $\left[{ }^{64} \mathrm{Cu}\right]$, DOTA-MEDI-522 has been found to show high specificity for tumor uptake by PET imaging in a U87MG tumor xenograft model [183]. Such finding is extremely important, as use of this technique can be very useful for evaluating the bioavailability, pharmacokinetic property and toxicity of a drug that's undergoing clinical trial. Kimura et al. has recently reported a novel way of tumor-specific PET imaging of integrins by the use of cystine-knot peptide. In this method they have incorporated the RGD-based integrin binding motif into the surface-exposed loop of the cystine knot peptide. The rigid structural scaffold of this peptide allowed high affinity binding to integrins like $\alpha v \beta 3, \alpha v \beta 5, \alpha 5 \beta 1$ and thus allowed high level of tumor specific uptake of the radiolabel [184]. Radiotracer based PET imaging is also being used for targeting $\alpha v \beta 6$ integrins. Increased expression of $\alpha v \beta 6$ is a common characteristic of many different cancers. For example, av $\beta 6$ expression becomes significantly high in OSCC [185]. Hausner et al. have recently reported an effective method of PET imaging of $\alpha v \beta 6$ by the use of a radiotracer $\left[{ }^{18} \mathrm{~F}\right]$ FBA-PEG28-A20FMDV2 (avB6 specific peptide labeled with $\left[{ }^{18} \mathrm{~F}\right]$ fluorobenzoyl) [186]. Use of this radiotracer allowed them to specifically label $\alpha v \beta 6$ in two different tumor xenograft models (one with melanoma cell line and the other pancreatic carcinoma cell line).

The current advancement in nanotechnology is also being utilized for PET or SPECT imaging of $\alpha v \beta 3$ receptor. The biggest advantage of nanoparticles in imaging is that a single nanoparticle can be loaded with thousands of imaging labels, which in turn increases the signal intensity. There are a number of examples of preclinical studies where labeled nanoparticles have been used in the PET imaging of tumors expressing $\alpha v \beta 3$. For example, in a recent work done by Liu et al., it has been shown that $\left[{ }^{64} \mathrm{Cu}\right]$-labeled single-walled carbon nanotubes (SWNTs) conjugated with C(RGDyK) peptide was very effective in targeting tumor in mouse models [187].

Molecular targeting of integrin receptors is also being coupled with magnetic resonance imaging (MRI). Molecular imaging of specific integrins by MRI utilizes both a paramagnetic substance like gadolinium (Gd) [175] and a ligand for the target integrin receptor along with a vehicle (liposome or nanoparticles) for targeted delivery of these two components. Schmieder et al. reported the use of MR imaging of $\alpha 5 \beta 1$ for the quantitative characterization of angiogenesis and evaluation of a $\alpha 5 \beta 1$-targeted peptidomimetic inhibitor of angiogenesis in a MDA-MB435 based tumor xenograft mouse model [188]. They used per-fluorocarbon (PFC) (paramagnetic) nanoparticles loaded with $\alpha 5 \beta 1$-targeted peptide for the imaging of neovasculature in the tumor area.

Biomarker based molecular imaging is also being utilized for ultra sound (US) imaging \& optical imaging (OI). Contrast enhanced ultra sound (CEU) imaging uses microbubbles as an intravascular contrast agent. Microbubles are usually made of hydrophobic vesicle loaded with perfluorocarbon gas $[189,190]$. Once inside the microvessels, these microbubbles can be burst by the application of high intensity ultra sound and that generates strong backscatter echo which can be utilized for measuring blood flow and blood volume. These microbubbles can be labeled on the surface for specific targeting of a molecular biomarker like $\alpha v \beta 3$ [175,176,190]. Willmann et al. combined the use of a cystine knot (knottin) peptide and contrast enhancing microbubbles for the ultrasound imaging of av $\beta 3$. RGD-motif containing knottin peptide was incorporated on the surface of perfluorocarbon filled microbubbles and while administered in vivo, they could obtain efficient ultra sound imaging of tumor angiogenesis in human ovarian adenocarcinoma xenografts [191]. Optical imaging (OI), such as near-infra red fluorescence imaging (NIRF) is also gaining importance for the targeted imaging of molecular biomarkers. With the advent of fluorescence mediated tomography (FMT) optical imaging is now capable of quantitative measurement too [175]. Fluorochromes are being targeted towards specific biomarkers such as $\alpha v \beta 3$ for the optical imaging of angiogenesis. For example, $\alpha v \beta 3$ targeting by Cy5.5-coupled RGD peptide has been utilized for the NIRF imaging of U87MG glioma tumor xenograft in mice [192]. Wallbrunn et al. later showed the quantitative measurement of $\alpha \mathrm{v} \beta 3$ expression by Cy5.5-RGD using FMT [193]. Though there are a number of disadvantages currently associated with this technique, like toxicity, short half-life and lack of quantifiability [194], significant research is being carried out for the further ad- 
vancement of this technique.

\subsection{Targeted Drug Delivery}

The concept of integrin-targeted drug delivery is based on two important characteristics. First, integrins can internalize once they are bound to their ligand and second, several integrin molecules show differential expression based on disease condition. It has been already mentioned that both $\alpha v \beta 3 \& \alpha v \beta 5$ are not highly expressed in quiescent endothelial cells, whereas their expression becomes several fold higher during angiogenesis. Several different tumor cells also show increased level of expression of $\alpha v \beta 3 \& \alpha v \beta 5$. Similar kinds of change in expression are also observed with $\alpha 5 \beta 1$ on endothelial cells [17]. Expression of $\alpha v \beta 6$ has been found to go up in different kinds of carcinoma, e.g. oral \& skin squoumous cell carcinoma (SSC), colon, pancreatic carcinoma etc. [97]. $\alpha v \beta 6$ expression has also been found to go up in keratinocytes during wound healing. Such increased expression related to certain kind of pathological condition can be effectively utilized for efficient drug delivery. The biggest problem with chemotherapeutic agents is their non-specific uptake by the healthy cells, which results in cytotoxicity. Another problem is the lack of penetration of chemotherapeutic agents in to the tumor site due to abnormal tumor vasculature. Both small molecule and biomacromolecule types of chemotherapeutic agents are being conjugated with integrin antagonists for the targeted delivery to the tumor site [195].

Currently, there are mainly two strategies that are being explored for integrin targeted drug delivery. In one approach, RGD-based peptides are being directly conjugated with chemotherapeutic agents, and in the other approach, integrin targeted nanoparticles are being used for drug delivery. Integrin targeted nanoparticles are also being explored for the targeted delivery of gene and siRNA [195]. Several research groups are currently involved in the targeted delivery of chemotherapeutics in RGD-conjugated form. One example is the conjugation of a very common chemotherapeutic drug, doxorubicin, with av-targeting peptide RGD4C. Arap et al. showed that RGD4C-conjugated doxorubicin had much better efficacy and less cytotoxicity while applied to breast cancer xenografts in nude mice [196], compared to the free drug. In another study, Burkhart et al. used cilengitide cyclic-(N-Me-VRGDf) for conjugation with doxaliform which is a derivative of doxorubicin (doxorubicin conjugated with formaldehyde and salicylamide) [197]. The structure of the cilengitide-doxaliform conjugate connected by a linear tether is shown in Figure 4(a). Use of this conjugated form allowed them to achieve better growth inhibition of MDA-MB-435 breast cancer cell compared to doxorubicin. Chen et al. reported the use of dimeric RGD peptide $\mathrm{E}[\mathrm{c}(\mathrm{RGDyK})] 2$ for con- jugation with another chemotherapeutic agent, paclitaxel. Conjugation was carried out by putting a succinate residue between the 2-hydroxyl group of paclitaxel and the amino group of glutamate residue of the dimeric RGD peptide [198]. The structure of this conjugate is shown in Figure 4(b). Use of this conjugate showed encouraging improvement in the uptake of paclitaxel and killing of MDA-MB-435 breast cancer cell line, compared to paclitaxel alone. Recently Pilkington-Miksa et al. showed that paclitaxel conjugated to cyclic azabicycloalkaneRGD via triazolyl containing linker had excellent antitumor activity in ovarian carcinoma xenograft in nude mice [199]. Beside small molecules tumor suppressing or proapoptotic cytokines are also being conjugated with an RGD-based peptide such as TNF- $\alpha$. Curnis et al. conjugated this molecule with a RGD-based peptide (ACDCRGDCFCG) and found that this conjugate showed better binding affinity to the TNF- $\alpha$ receptor and could produce an antineoplastic effect in very low dose [200].

Integrin-targeting ligands are also being used along with nanoparticle-based delivery system. There is a number of different nanoparticle-based delivery system available at this point, e.g. liposome, polymersome, micelles, polymeric nanospheres etc. [195]. Integrin targeting ligands, especially RGD-based peptides are being incorporated on to the nanoparticle mainly via surface modification. The therapeutic agent, on the other hand, is either encapsulated or sometimes conjugated with the nanoparticles. Such modification brings additional advantage of increased stability, bioavailability and decreased side effect of the therapeutic agent. Integrin targeted nanoparticles are also being used for the targeted delivery of gene or siRNA. There are several examples where different nanoparticle-based delivery systems have been utilized for targeted delivery of chemotherapeutic agents. Danhier et al. reported the use of a PEGylated PLGA (poly(lactic-co-glycolic acid)) based nanosphere system for the targeted delivery of paclitaxel to cancer cells. These nanoparticles were surface modified by RGD peptide or RGD-peptidomimetic and loaded with paclitaxel [201]. These nanoparticles showed much improved targeting of integrin over-expressing HUVEC cells and also stronger retardation of tumor growth compared to the free drug. Integrin targeted nanoparticle-based drug delivery systems are not only being utilized for the treatment of cancer. They have also been utilized for the targeted delivery of antiangiogenic drugs in the treatment of rheumatoid arthritis. Zhou et al. utilized PFC nanoparticle conjugated to an RGD-peptidomimetic antagonist of $\alpha v \beta 3$ and loaded it with the antiangiogenic substance fumagillin. Application of fumagillin through such system allowed targeted deliv- 


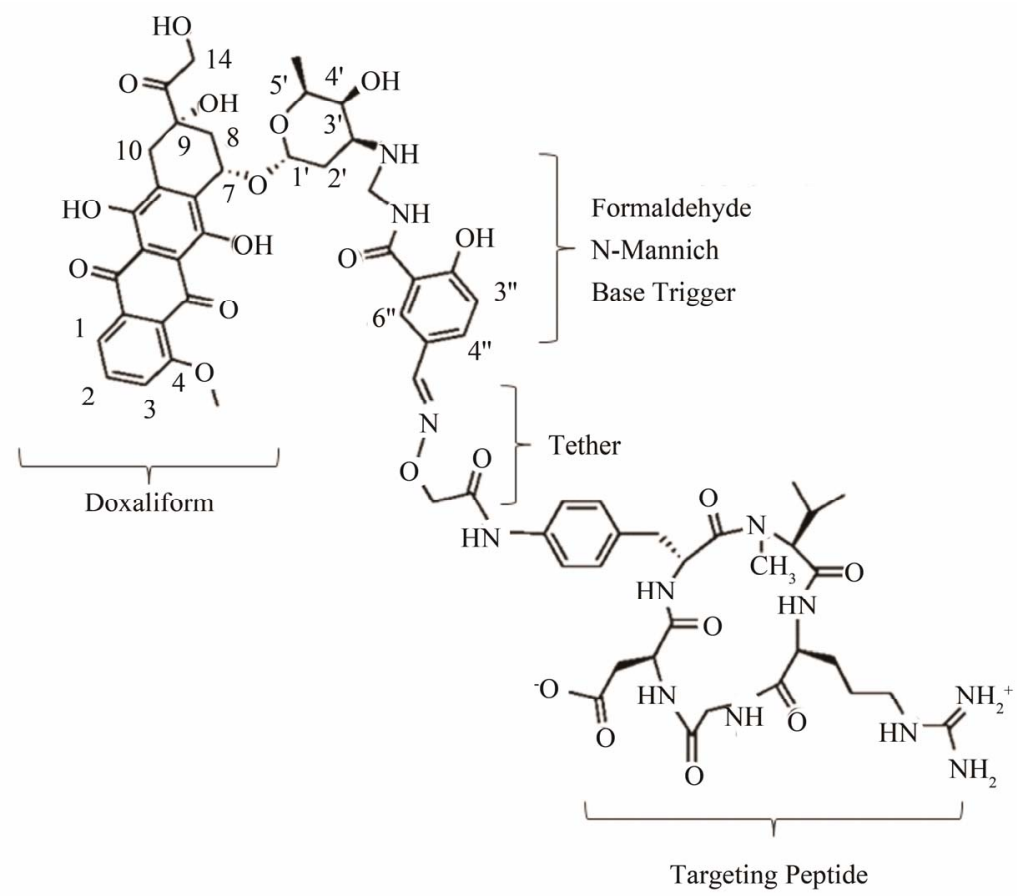

(a)

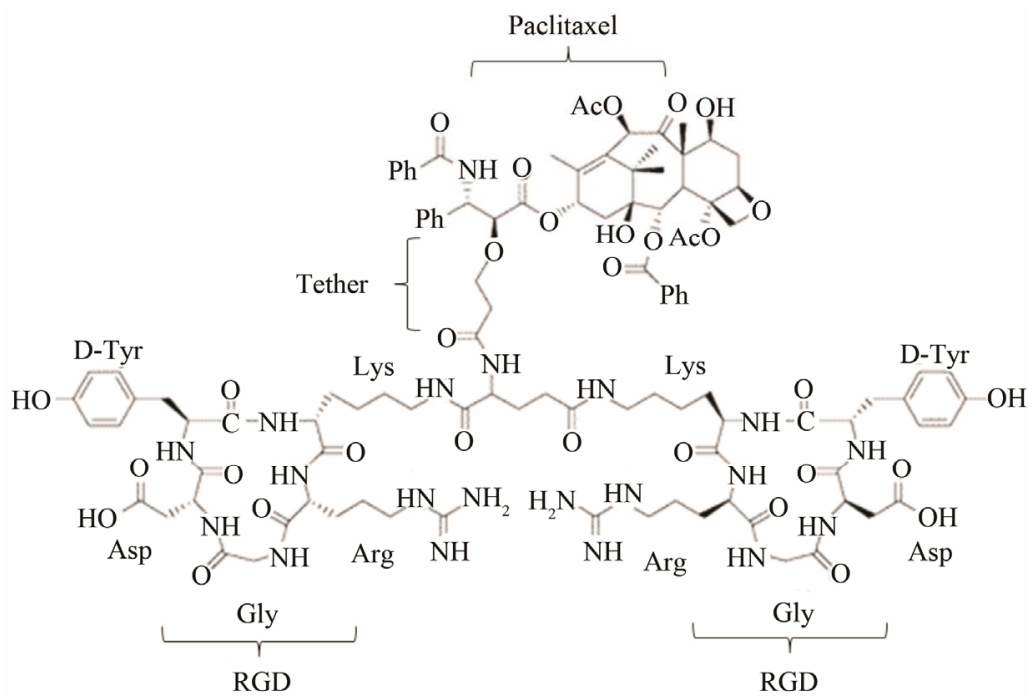

(b)

Figure 4. This figure includes the example of integrin targeted drug delivery where direct conjugation of the chemotherapeutics with RGD based peptides has been carried out. Panel-a shows an example where cilengitide (RGD containing cyclic pentapetide) has been conjugated with doxaliform (chemotherapeutic agent). Panel-b shows another example where chemotherapeutic agent paclitaxel has been conjugated with dimeric RGD peptide.

ery to the inflamed joint and resulted in much better suppression of arthritis progression in the mouse model of arthritis [202].

One of the major concerns of gene therapy is the targeted delivery of the DNA to the site of action. DNA is a charged biomolecule, which makes penetration through the tissue energetically unfavorable. Moreover, DNA is highly susceptible to enzymatic degradation. Encapsulation of DNA into a nanoparticle-based delivery system may overcome these problems to some extent. Recently, nanoparticles conjugated with integrin-targeting ligands are being studied for the targeted delivery of DNA to the tissue. Hood et al. in a ground-breaking study, showed how integrin targeting ligand-containing nanoparticles 
can be utilized for targeted gene delivery. In that study they covalently coupled an RGD mimetic ligand to cationic polymerized lipid based nanoparticles and loaded the nanoparticles with a mutant of the Raf- 1 gene [203]. The mutant gene loaded nanoparticles were applied to the M21 melanoma cell induced tumor. Targeted delivery of the gene was confirmed by observing the responses as would be expected from the mutant version of Raf-1. Bhattacharya et al., in a recent study reported the delivery of a plasmid, encoding platelet-derived growth factor- $\beta$ (PDGF- $\beta$ ) gene, through a liposome made of RGDK-lipopeptide in to the site of diabetic wound. A single subcutaneous administration of this plasmid through this delivery method resulted in sufficient wound healing. They also found that the intra-cellular delivery of this gene was $\alpha 5 \beta 1$ mediated [204]. Integrin targeted delivery systems are also being studied extensively for the delivery of siRNA. A very recent example is the targeted delivery of cyclin-D1 siRNA to leukocytes associated with colitis, via an $\alpha 7$ antibody-coupled liposome. Such targeted delivery caused reduction in cyclin-D1 expression and also a reduction in inflammation associated with colitis [205]. Targeted delivery of siRNA is also being studied with poly (amidoamine)-dendrimer (PAMAM), which is a highly branched synthetic polymer. In a study by Waite et al., PANAM-RGD conjugate system was utilized for the delivery of siRNA in to a 3dimensional multicellular tumor spheroid (MTCS) model of U87 glioma cells [206]. It was found that presence of RGD resulted in a much better penetration of the delivery system through the 3-dimensional scaffold of the tumor and thus allowed more effective delivery of the siRNA.

\section{CONCLUSIONS}

The major focus of this review has been to explore the various medical purposes that integrins receptors are involved at. A thorough discussion has been carried out on different integrin receptors, their role in different disease models and on how they are being therapeutically targeted. A special emphasis has been given on $\alpha v \beta 3$ \& $\alpha v \beta 5$, because they remain as the two most extensively explored integrins to date. These two integrins are the major target for inhibition of angiogenesis and inhibitors targeted to them have been trialed in several preclinical and clinical studies. A number of inhibitors of $\alpha v \beta 3$ \& $\alpha v \beta 5$ have been subject to clinical trials for the treatment of cancer and there are huge numbers of drugs that are being studied at preclinical stage. Inhibition of $\alpha v \beta 3$ \& $\alpha v \beta 5$ has been targeted for treatment of other kinds of pathological conditions, like rheumatoid arthritis and vascular disorders, where angiogenesis plays a key role in disease progression. A number of inhibitors are currently under clinical trial for the treatment of these con- ditions. Unfortunately, so far there is only one drug (cilengitide, a potent inhibitor of $\alpha v \beta 3$ ) that has made into phase-III clinical trials for the treatment of glioblastoma multiforme (GBM). Though it was trialed at phaseII level for the treatment of different kinds of cancers, including prostate cancer and stage-III/V myeloma, only patients with GMB showed promising results. This tells us about the inherent complicacy of integrin biology. Though significant improvement has been made in last few years for understanding how integrins are involved in certain disease conditions, more in depth understanding is still needed. In this review we have noticed that therapeutic targeting is not only limited to $\alpha v \beta 3 \& \alpha \mathrm{v} \beta 5$; there are many other kinds of integrins that are gaining importance as potential drug targets, due to their serious involvement with many disease conditions. For example, targeting $\alpha 4$ integrins have given us a number of drugs that are currently under evaluation at clinical trials for the treatment of several inflammatory conditions like IBD \& MS. Targeting of $\alpha \operatorname{IIb} \beta 3$ have resulted in three drugs that are currently being marketed for the prevention of coronary events in patients undergoing angioplasty or other kind of coronary intervention. Unfortunately, all the orally available inhibitors of $\alpha \operatorname{IIb} \beta 3$ failed at phase-III clinical trial. This once again points towards the fact of how complicated the role integrins may play in modulating certain disease conditions, and a complete understanding of that role will be the key to the development of successful therapeutic application. Nevertheless, therapeutic targeting of integrin receptors holds a great promise and it is expected that with the ongoing advancement of science \& technology, there will be more effective means of targeting integrins available to us. It seems that the continuous growth of our knowledge in integrin biology will eventually lead us to a much more coherent understanding of the role of each integrin plays. We have discussed the role of integrin $\alpha v \beta 3$ in the development osteoporosis. Recently Lemieux et al. reported the involvement of $\alpha 3 \beta 1 \& \alpha 5 \beta 1$ in the development of osteoporosis [207]. They found that these two integrins are expressed on the surface of hematopoietic cell, like megakaryocytes and play a crucial role in the megakaryocyte cell mediated osteoblast differentiation. Cordes \& Park, in a review article discussed the importance of inhibiting $\beta 1$ integrin for improving the prospect of radiation therapy in cancer [208]. $\beta 1$ integrin has been known to provide important survival signals to the tumor cell in a post radiation situation. Inhibiting this integrin may improve the efficacy of radiation therapy. Thus our knowledge in integrin biology is mounting and will prove to be highly beneficial for effective therapeutic strategies.

We have also discussed the potential of targeting integrin receptors for diagnostic imaging and for evalu- 
ating the efficacy of a drug. We have also seen how cell surface integrin expression is being utilized for the targeted delivery of drug. Different strategies for both diagnosis and drug delivery have been discussed. Currently, $\alpha v \beta 3$ is the main integrin that has been extensively studied for both diagnosis and drug delivery, though there are others that are gaining more importance. Though we have come across different approaches for targeted imaging of $\alpha v \beta 3$ expression on tumor cells, only a radiotracer-based approach has been transitioned to trial at clinical level. For example, $\left[{ }^{18} \mathrm{~F}\right]$ galacto-RGD is the first av 33 -targeted radiotracer used for PET imaging of malignant tumor cells in patients. This was found to show successful imaging of $\alpha \mathrm{v} \beta 3$ expression with good tumor to background ratio [209]. Integrin targeted drug delivery still has not transitioned into clinical trials and significant improvement is still needed for effectively targeting strategies. At the end we can conclude that though there are several issues that are still in need of careful evaluation for successful targeting, integrin receptors possess tremendous prospect for designing novel strategies for addressing different disease conditions.

\section{ACKNOWLEDGEMENTS}

I acknowledge Todd Schoborg (Graduate student at University of Tennessee, Knoxville), Dr. Tapan das (Associate Research Fellow, Pharmaceutical R \& D, Biotherapeutics, Pfizer) and Dr. Satoshi Ohtake (Senior Principal Scientist, Pharmaceutical R \& D, Biotherapeutics, Pfizer) for their valuable advice.

\section{REFERENCES}

[1] Hynes, R.O. (2004) The emergence of integrins: A personal and historical perspective. Matrix Biology, 23, 333-340. doi:10.1016/j.matbio.2004.08.001

[2] Tamkun, J.W., et al. (1986) Structure of integrin, a glycoprotein involved in the transmembrane linkage between fibronectin and actin. Cell, 46, 271-282. doi:10.1016/0092-8674(86)90744-0

[3] Stupack, D.G. (2007) The biology of integrins. Oncology, 21, 6-12.

[4] Barczyk, M., Carracedo, S. and Gullberg, D. (2010). Integrins. Cell and Tissue Research, 339, 269-280. doi:10.1007/s00441-009-0834-6

[5] Humphries, M.J., Symonds, E.J. and Mould, A.P. (2003) Mapping functional residues onto integrin crystal structures. Current Opinion in Structural Biology, 13, 236-243. doi:10.1016/S0959-440X(03)00035-6

[6] Curley, G.P., Blum, H. and Humphries, M.J. (1999). Integrin antagonists. Cellular and Molecular Life Sciences, 56, 427-441. doi:10.1007/s000180050443

[7] Larson, R.S., et al. (1989) Primary structure of the leukocyte function-associated molecule-1 alpha subunit: An integrin with an embedded domain defining a protein superfamily. The Journal of Cell Biology, 108, 703-712. doi:10.1083/jcb.108.2.703

[8] Askari, J.A., et al. (2009) Linking integrin conformation to function. Journal of Cell Science, 122,165-170. doi: $10.1242 /$ jcs. 018556

[9] Calvete, J.J. (2004) Structures of integrin domains and concerted conformational changes in the bidirectional signaling mechanism of alphallbbeta3. Experimental Biology and Medicine, 229, 732-744.

[10] Gahmberg, C.G., et al. (2009) Regulation of integrin activity and signalling. Biochimica et Biophysica Acta, 1790, 431-444. doi:10.1016/j.bbagen.2009.03.007

[11] Honda, S., et al. (2009) Integrin-linked kinase associated with integrin activation. Blood, 113, 5304-5313. doi:10.1182/blood-2008-07-169136

[12] Giancotti, F.G. and Ruoslahti, E. (1999) Integrin signaling. Science, 285, 1028-1032. doi:10.1126/science.285.5430.1028

[13] Brooks, P.C., Clark, R.A. and Cheresh, D.A. (1994) Requirement of vascular integrin alphavbeta3 for angiogenesis. Science, 264, 569-571. doi:10.1126/science.7512751

[14] Storgard, C.M., et al. (1999) Decreased angiogenesis and arthritic disease in rabbits treated with an alphavbeta3 antagonist. Journal of Clinical Investigation, 103, 47-54. doi:10.1172/JCI3756

[15] Horton, M.A., et al. (1991) Arg-Gly-Asp (RGD) peptides and the anti-vitronectin receptor antibody 23C6 inhibit dentine resorption and cell spreading by osteoclasts. Experimental Cell Research, 195, 368-375. doi:10.1016/0014-4827(91)90386-9

[16] Davenport, R.J. and J.R. Munday, (2007) Alpha4-integrin antagonism-An effective approach for the treatment of inflammatory diseases? Drug Discovery Today, 12, 569576. doi:10.1016/j.drudis.2007.05.001

[17] Kim, S., et al. (2000) Regulation of angiogenesis in vivo by ligation of integrin alpha5betal with the central cell-binding domain of fibronectin. American Journal of Pathology, 156, 1345-1362. doi:10.1016/S0002-9440(10)65005-5

[18] Goodman, S.L. and Picard, M. (2012) Integrins as therapeutic targets. Trends in Pharmacological Sciences, 33, 405-412. doi:10.1016/j.tips.2012.04.002

[19] Byron, A., et al. (2009) Anti-integrin monoclonal antibodies. Journal of Cell Science, 122, 4009-4011. doi: $10.1242 /$ jcs. 056770

[20] Mould, A.P., Akiyama, S.K. and Humphries, M.J. (1996) The inhibitory anti-betal integrin monoclonal antibody 13 recognizes an epitope that is attenuated by ligand occupancy. Evidence for allosteric inhibition of integrin function. The Journal of Biological Chemistry, 271, 20365-20374. doi:10.1074/jbc.271.34.20365

[21] Artoni, A., et al. (2004) Integrin beta3 regions controlling binding of murine mAb 7E3: implications for the mechanism of integrin alphaIIbbeta3 activation. Proceedings of the National Academy of Sciences of the United States of America, 101, 13114-13120. doi:10.1073/pnas.0404201101

[22] Weinreb, P.H., et al. (2004) Function-blocking integrin 
alphavbeta6 monoclonal antibodies: Distinct ligand-mimetic and nonligand-mimetic classes. The Journal of Biological Chemistry, 279, 17875-17887. doi:10.1074/jbc.M312103200

[23] Deckmyn, H., et al. (1994) An echistatin-like Arg-GlyAsp (RGD)-containing sequence in the heavy chain CDR3 of a murine monoclonal antibody that inhibits human platelet glycoprotein IIb/IIIa function. British Journal of Haematology, 87, 562-571. doi:10.1111/j.1365-2141.1994.tb08313.x

[24] Hynes, R.O., (2002) Integrins: Bidirectional, allosteric signaling machines. Cell, 110, 673-687. doi:10.1016/S0092-8674(02)00971-6

[25] Nagarajan, S.R., et al. (2007) R-isomers of Arg-Gly-Asp (RGD) mimics as potent alphavbeta3 inhibitors. Bioorganic \& Medicinal Chemistry, 15, 3783-3800. doi:10.1016/j.bmc.2007.03.034

[26] Xiong, J.P., et al. (2002) Crystal structure of the extracellular segment of integrin alphavbeta3 in complex with an Arg-Gly-Asp ligand. Science, 296, 151-155. doi:10.1126/science. 1069040

[27] Liu, Z., Wang, F. and Chen, X. (2008) Integrin avb3Targeted Cancer Therapy. Drug Development Research, 69, 329-339. doi:10.1002/ddr.20265

[28] Eble, J.A. and Haier, J. (2006) Integrins in cancer treatment. Current Cancer Drug Targets, 6, 89-105. doi: $10.2174 / 156800906776056518$

[29] Tucker, G.C. (2003) Alpha v integrin inhibitors and cancer therapy. Current Opinion in Investigational Drugs, 4 , 722-731.

[30] Tucker, G.C. (2006) Integrins: Molecular targets in cancer therapy. Current Oncology Reports, 8, 96-103. doi:10.1007/s11912-006-0043-3

[31] Kimura, R.H., et al. (2009) Engineered cystine knot peptides that bind alphavbeta3, alphavbeta5, and alpha5beta 1 integrins with low-nanomolar affinity. Proteins, 77, 359369. doi: $10.1002 /$ prot. 22441

[32] Huang, T.F. (1998) What have snakes taught us about integrins? Cellular and Molecular Life Sciences, 54, 527-540. doi:10.1007/s000180050181

[33] Yeh, C.H., et al. (2001) Rhodostomin, a snake venom disintegrin, inhibits angiogenesis elicited by basic fibroblast growth factor and suppresses tumor growth by a selective alphavbeta3 blockade of endothelial cells. Molecular Pharmacology, 59, 1333-1342.

[34] Swenson, S., et al. (2004) Intravenous liposomal delivery of the snake venom disintegrin contortrostatin limits breast cancer progression. Molecular Cancer Therapeutics, 3, 499-511.

[35] Aota, S., Nomizu, M. and Yamada, K.M. (1994) The short amino acid sequence Pro-His-Ser-Arg-Asn in human fibronectin enhances cell-adhesive function. The Journal of Biological Chemistry, 269, 24756-24761.

[36] Maeshima, Y., Colorado, P.C. and Kalluri, R. (2000) Two RGD-independent alphavbeta3 integrin binding sites on tumstatin regulate distinct anti-tumor properties. The Journal of Biological Chemistry, 275, 23745-23750. doi:10.1074/jbc.C000186200
[37] Thevenard, J., et al. (2010) The YSNSG cyclopeptide derived from tumstatin inhibits tumor angiogenesis by down-regulating endothelial cell migration. International Journal of Cancer, 126, 1055-1066.

[38] Castel, S., et al. (2001) RGD peptides and monoclonal antibodies, antagonists of alpha v-integrin, enter the cells by independent endocytic pathways. Laboratory Investigation, 81, 1615-1626. doi:10.1038/labinvest.3780375

[39] Paolillo, M., et al. (2009) Small molecule integrin antagonists in cancer therapy. Mini-Reviews in Medicinal Chemistry, 9, 1439-1446. doi: $10.2174 / 138955709789957404$

[40] Heckmann, D., et al. (2009) Breaking the dogma of the metal-coordinating carboxylate group in integrin ligands: Introducing hydroxamic acids to the MIDAS to tune potency and selectivity. Angewandte Chemie International Edition, 48, 4436-4440. doi:10.1002/anie.200900206

[41] Duggan, M.E. and Hutchinson, J.H. (2000) Ligands to the integrin receptor $\alpha \mathrm{v} \beta 3$. Expert opinion in therapeutic patents. 10, 1367-1383. doi:10.1517/13543776.10.9.1367

[42] Hutchinson, J.H., et al. (2003) Nonpeptide alphavbeta3 antagonists. 8. In vitro and in vivo evaluation of a potent alphavbeta3 antagonist for the prevention and treatment of osteoporosis. Journal of Medicinal Chemistry, 46, 4790-4798. doi:10.1021/jm030306r

[43] Murphy, M.G., et al. (2005) Effect of L-000845704, an alphavbeta3 integrin antagonist, on markers of bone turnover and bone mineral density in postmenopausal osteoporotic women. The Journal of Clinical Endocrinology \& Metabolism, 90, 2022-2028. doi: $10.1210 /$ jc. $2004-2126$

[44] Komoriya, A., et al. (1991) The minimal essential sequence for a major cell type-specific adhesion site (CS1) within the alternatively spliced type III connecting segment domain of fibronectin is leucine-aspartic acid-valine. The Journal of Biological Chemistry, 266, 15075-15079.

[45] Newham, P., et al. ((1997)).Alpha4 integrin binding interfaces on VCAM-1 and MAdCAM-1. Integrin binding footprints identify accessory binding sites that play a role in integrin specificity. The Journal of Biological Chemistry, 272, 19429-19440. doi:10.1074/jbc.272.31.19429

[46] Lin, K., et al. (1999) Selective, tight-binding inhibitors of integrin alpha4betal that inhibit allergic airway responses. Journal of Medicinal Chemistry, 42, 920-934. doi:10.1021/jm980673g

[47] Hijazi, Y., et al. (2004) Pharmacokinetics, safety, and tolerability of R411, a dual alpha4beta1-alpha4beta7 integrin antagonist after oral administration at single and multiple once-daily ascending doses in healthy volunteers. The Journal of Clinical Pharmacology, 44, 1368-78. doi:10.1177/0091270004270147

[48] Kumar, C.C. (2003) Integrin alphavbeta3 as a therapeutic target for blocking tumor-induced angiogenesis. Current Drug Targets, 4, 123-131. doi:10.2174/1389450033346830

[49] Mousa, S.A. (2002) Anti-integrin as novel drug-discovery targets: Potential therapeutic and diagnostic implications. Current Opinion in Chemical Biology, 6, 534-541. 


\section{doi:10.1016/S1367-5931(02)00350-2}

[50] Mousa, S.A. (2003) Alphav vitronectin receptors in vascular-mediated disorders. Medicinal Research Reviews, 23,190-199. doi:10.1002/med.10031

[51] Goldring, S.R. and Gravallese, E.M. (2000) Pathogenesis of bone erosions in rheumatoid arthritis. Current Opinion in Rheumatology, 12,195-199. doi:10.1097/00002281-200005000-00006

[52] Albelda, S.M., et al. (1990) Integrin distribution in malignant melanoma: Association of the beta3 subunit with tumor progression. Cancer Research, 50, 6757-6764.

[53] Gladson, C.L. and Cheresh, D.A. (1991) Glioblastoma expression of vitronectin and the alphavbeta3 integrin. Adhesion mechanism for transformed glial cells. Journal of Clinical Investigation, 88, 1924-1932. doi:10.1172/JCI115516

[54] Hanahan, D. and Folkman, J. (1996) Patterns and emerging mechanisms of the angiogenic switch during tumorigenesis. Cell, 86, 353-364. doi:10.1016/S0092-8674(00)80108-7

[55] Ruegg, C., Dormond, O. and Foletti, A. (2002) Suppression of tumor angiogenesis through the inhibition of integrin function and signaling in endothelial cells: Which side to target? Endothelium, 9, 151-160. doi:10.1080/10623320213635

[56] Weidner, N., et al. (1991) Tumor angiogenesis and metastasis-correlation in invasive breast carcinoma. The New England Journal of Medicine, 324, 1-8. doi:10.1056/NEJM199101033240101

[57] Mizejewski, G.J. (1999) Role of integrins in cancer: Survey of expression patterns. Proceedings of the Society for Experimental Biology and Medicine, 222, 124-138. doi:10.1046/j.1525-1373.1999.d01-122.x

[58] Tucker, G.C. (2002) Inhibitors of integrins. Current Opinion in Pharmacology, 2, 394-402. doi:10.1016/S1471-4892(02)00175-3

[59] Friedlander, M., et al. (1995) Definition of two angiogenic pathways by distinct alpha $\mathrm{v}$ integrins. Science, 270, 1500-1502. doi:10.1126/science.270.5241.1500

[60] MacDonald, T.J., et al. (2001) Preferential susceptibility of brain tumors to the antiangiogenic effects of an alpha $\mathrm{V}$ integrin antagonist. Neurosurgery, 48, 151-157.

[61] Taga, T., et al. (2002) Alphav-integrin antagonist EMD 121974 induces apoptosis in brain tumor cells growing on vitronectin and tenascin. International Journal of Cancer, 98, 690-697. doi:10.1002/ijc.10265

[62] Colevas, A.D., Scharf, O. and Schoenfeldt, M. (2004) Clinical trials referral resource. Current clinical trials of cilengitide, an alphav antagonist in clinical development as an anticancer agent. Oncology, 18, 1778, 1781-1782, 1784.

[63] Reardon, D.A., et al. (2008) Cilengitide: An integrintargeting arginine-glycine-aspartic acid peptide with promising activity for glioblastoma multiforme. Expert Opinion on Investigational Drugs, 17, 1225-1235. doi:10.1517/13543784.17.8.1225

[64] Weller, M., et al. (2009) Will integrin inhibitors have proangiogenic effects in the clinic? Nature Medicine, 15, 726. doi: $10.1517 / 13543784.17 .8 .1225$

[65] Kurozumi, K., et al. (2012) Cilengitide treatment for malignant glioma: Current status and future direction. Neurologia Medico-Chirurgica, 52, 539-547. doi:10.2176/nmc.52.539

[66] Manegold, C., et al. (2012) Randomized phase II study of three doses of the integrin inhibitor cilengitide versus docetaxel as second-line treatment for patients with advanced non-small-cell lung cancer. Investigational New Drugs, 31, 175-182.

[67] Wu, H., et al. (1998) Stepwise in vitro affinity maturation of Vitaxin, an alphavbeta3-specific humanized mAb. Proceedings of the National Academy of Sciences of the United States of America, 95, 6037-6042. doi:10.1073/pnas.95.11.6037

[68] Trikha, M., et al. (2004) CNTO 95, a fully human monoclonal antibody that inhibits alphav integrins, has antitumor and antiangiogenic activity in vivo. International Journal of Cancer, 110, 326-335. doi:10.1002/ijc.20116

[69] Goel, H.L., et al. (2008) Integrins in prostate cancer progression. Endocrine-Related Cancer, 15, 657-664. doi:10.1677/ERC-08-0019

[70] Liaw, L., et al. (1995) The adhesive and migratory effects of osteopontin are mediated via distinct cell surface integrins. Role of alphavbeta 3 in smooth muscle cell migration to osteopontin in vitro. Journal of Clinical Investigation, 95, 713-724. doi:10.1172/JCI117718

[71] Choi, E.T., et al. (1994) Inhibition of neointimal hyperplasia by blocking alphavbeta3 integrin with a small peptide antagonist GpenGRGDSPCA. Journal of Vascular Surgery, 19, 125-134. doi:10.1016/S0741-5214(94)70127-X

[72] Bishop, G.G., et al. (2001) Selective alphavbeta3-receptor blockade reduces macrophage infiltration and restenosis after balloon angioplasty in the atherosclerotic rabbit. Circulation, 103, 1906-1911. doi:10.1161/01.CIR.103.14.1906

[73] Coleman, K.R., et al. (1999). Vitaxin, a humanized monoclonal antibody to the vitronectin receptor (alphavbeta3), reduces neointimal hyperplasia and total vessel area after balloon injury in hypercholesterolemic rabbits. Circulation Research, 84, 1268-1276. doi:10.1161/01.RES.84.11.1268

[74] Teitelbaum, S.L. (2000) Bone resorption by osteoclasts. Science, 289, 1504-1508. doi:10.1126/science.289.5484.1504

[75] Parfitt, A.M. (1994) Osteonal and hemi-osteonal remodeling: the spatial and temporal framework for signal traffic in adult human bone. Journal of Cellular Biochemistry, 55, 273-286. doi:10.1002/jcb.240550303

[76] Teitelbaum, S.L. (2000) Osteoclasts, integrins, and osteoporosis. Journal of Bone and Mineral Metabolism, 18, 344-349. doi:10.1007/s007740070007

[77] McHugh, K.P., et al. (2000) Mice lacking beta3 integrins are osteosclerotic because of dysfunctional osteoclasts. Journal of Clinical Investigation, 105, 433-440. doi:10.1172/JCI8905 
[78] Ross, F.P., et al. (1993) Interactions between the bone matrix proteins osteopontin and bone sialoprotein and the osteoclast integrin alphavbeta3 potentiate bone resorption. The Journal of Biological Chemistry, 268, 99019907.

[79] Engleman, V.W., et al. (1997) A peptidomimetic antagonist of the alphavbeta3 integrin inhibits bone resorption in vitro and prevents osteoporosis in vivo. Journal of Clinical Investigation, 99, 2284-2292. doi:10.1172/JCI119404

[80] McCabe, C.J. and Akehurst, R.L. (1997) Health economics in rheumatology. Baillière's Clinical Rheumatology, 11, 145-156. doi:10.1016/S0950-3579(97)80038-6

[81] Stupack, D.G., Storgard, C.M. and Cheresh, D.A. (1999) A role for angiogenesis in rheumatoid arthritis. Brazilian Journal of Medical and Biological Research, 32, 573581. doi:10.1590/S0100-879X1999000500011

[82] Kimball, E.S. and Gross, J.L. (1991) Angiogenesis in pannus formation. Agents Actions, 34, 329-331. doi:10.1007/BF01988724

[83] Ainola, M.M., et al. (2005) Pannus invasion and cartilage degradation in rheumatoid arthritis: Involvement of MM P-3 and interleukin-1beta. Clinical and Experimental Rheumatology, 23, 644-650.

[84] Koch, A.E. (1998) Review: Angiogenesis: Implications for rheumatoid arthritis. Arthritis \& Rheumatism, 41, 951-962. doi:10.1002/1529-0131(199806)41:6<951::AID-ART2>3 .0.CO;2-D

[85] Colville-Nash, P.R. and Scott, D.L. (1992) Angiogenesis and rheumatoid arthritis: Pathogenic and therapeutic implications. Annals of the Rheumatic Diseases, 51, 919925.

[86] Wilder, R.L., (2002) Integrin alphavbeta3 as a target for treatment of rheumatoid arthritis and related rheumatic diseases. Annals of the Rheumatic Diseases, 61, ii96-99. doi:10.1136/ard.51.7.919

[87] Paleolog, E., (1997) Target effector role of vascular endothelium in the inflammatory response: Insights from the clinical trial of anti-TNF alpha antibody in rheumatoid arthritis. Molecular Pathology, 50, 225-233. doi:10.1136/mp.50.5.225

[88] Badger, A.M., et al. (2001) Disease-modifying activity of SB 273005, an orally active, nonpeptide alphavbeta3 (vitronectin receptor) antagonist, in rat adjuvant-induced arthritis. Arthritis \& Rheumatism, 44, 128-137. doi:10.1002/1529-0131(200101)44:1<128::AID-ANR17 3.0.CO;2-M

[89] Luna, J., et al. (1996) Antagonists of integrin alphavbeta3 inhibit retinal neovascularization in a murine model. Laboratory Investigation, 75, 563-573.

[90] Hammes, H.P., et al. (1996) Subcutaneous injection of a cyclic peptide antagonist of vitronectin receptor-type integrins inhibits retinal neovascularization. Nature Medicine, 2, 529-533. doi:10.1038/nm0596-529

[91] Yasukawa, T., et al. (2004) Inhibition of experimental choroidal neovascularization in rats by an alphav-integrin antagonist. Current Eye Research, 28, 359-366. doi:10.1076/ceyr.28.5.359.28678

[92] Santulli, R.J., et al. (2008) Studies with an orally bioavailable alpha $\mathrm{v}$ integrin antagonist in animal models of ocular vasculopathy: retinal neovascularization in mice and retinal vascular permeability in diabetic rats. Journal of Pharmacology and Experimental Therapeutics, 324, 894-901. doi:10.1124/jpet.107.131656

[93] Coutre, S. and Leung, L. (1995) Novel antithrombotic therapeutics targeted against platelet glycoprotein IIb/IIIa. Annual Review of Medicine, 46, 257-265. doi:10.1146/annurev.med.46.1.257

[94] Jordan, R.E., Wagner, C.L., Mascelli, M., Treacy, G., Nedelman, M.A. and Woody, J.N. (1996) Preclinical development of c7E3 Fab; a mouse/human chimeric monoclonal antibody fragment that inhibits platelet function by blocking of GPIIb/IIIa receptors with the observations on the immunogenicity of c7E3 Fab in humans. In: Horton, M.A., Ed., Adhesion Receptors as Therapeutic Targets, CRC Press, Boca Raton, 281-305.

[95] Breuss, J.M., et al. (1993) Restricted distribution of integrin beta 6 mRNA in primate epithelial tissues. Journal of Histochemistry \& Cytochemistry, 41, 1521-1527. doi:10.1177/41.10.8245410

[96] Breuss, J.M., et al. (1995) Expression of the beta6 integrin subunit in development, neoplasia and tissue repair suggests a role in epithelial remodeling. Journal of Cell Science, 108, 2241-2251.

[97] Thomas, G.J., Nystrom, M.L. and Marshall, J.F. (2006) Alphavbeta6 integrin in wound healing and cancer of the oral cavity. Journal of Oral Pathology \& Medicine, 35, 1-10. doi:10.1111/j.1600-0714.2005.00374.x

[98] Busk, M., Pytela, R. and Sheppard, D. (1992) Characterization of the integrin alphavbeta6 as a fibronectinbinding protein. The Journal of Biological Chemistry, 267, 5790-5796.

[99] Thomas, G.J., et al. (2001) Alphavbeta6 Integrin upregulates matrix metalloproteinase 9 and promotes migration of normal oral keratinocytes. Journal of Investigative Dermatology, 116, 898-904. doi:10.1046/j.1523-1747.2001.01352.x

[100] Clark, R.A., et al. (1996) Re-epithelialization of normal human excisional wounds is associated with a switch from alphavbeta5 to alphavbeta6 integrins. British Journal of Dermatology, 135, 46-51. doi:10.1111/j.1365-2133.1996.tb03606.x

[101] Haapasalmi, K., et al. (1996) Keratinocytes in human wounds express alphavbeta6 integrin. Journal of Investigative Dermatology, 106, 42-48. doi:10.1111/1523-1747.ep12327199

[102] Verrecchia, F. and Mauviel, A. (2002) Transforming growth factor-beta signaling through the Smad pathway: Role in extracellular matrix gene expression and regulation. Journal of Investigative Dermatology, 118, 211-215. doi:10.1046/j.1523-1747.2002.01641.x

[103] Hsiao, J.R., et al. (2009) Cyclic alphavbeta6-targeting peptide selected from biopanning with clinical potential for head and neck squamous cell carcinoma. Head \& Neck, 32, 160-172.

[104] Thomas, G.J., et al. (2001) Expression of the alphav 
beta6 integrin promotes migration and invasion in squamous carcinoma cells. Journal of Investigative Dermatology, 117, 67-73. doi:10.1046/j.0022-202x.2001.01379.x

[105] Ramos, D.M., et al. (2002) Expression of integrin beta 6 enhances invasive behavior in oral squamous cell carcinoma. Matrix Biology, 21, 297-307. doi:10.1016/S0945-053X(02)00002-1

[106] Xue, H., et al. (2001) Role of the alpha v beta6 integrin in human oral squamous cell carcinoma growth in vivo and in vitro. Biochemical and Biophysical Research Communications, 288, 610-618. doi:10.1006/bbrc. 2001.5813

[107] Gleizes, P.E., et al. (1997) TGF-beta latency: Biological significance and mechanisms of activation. Stem Cells, 15, 190-197. doi:10.1002/stem.150190

[108] Miyazono, K., et al. (1988) Latent high molecular weight complex of transforming growth factor beta1. Purification from human platelets and structural characterization. The Journal of Biological Chemistry, 263, 6407-6415.

[109] Lawrence, D.A., (2001) Latent-TGF-beta: An overview. Molecular and Cellular Biochemistry, 219, 163-170. doi:10.1023/A:1010819716023

[110] Sheppard, D. (2008) The role of integrins in pulmonary fibrosis. European Rspiratory Review, 17, 157-162. doi:10.1183/09059180.00010909

[111] Munger, J.S., et al. (1999) The integrin alphavbeta6 binds and activates latent TGF beta 1: A mechanism for regulating pulmonary inflammation and fibrosis. Cell, 96, 319-328. doi:10.1016/S0092-8674(00)80545-0

[112] Annes, J.P., Rifkin, D.B. and Munger, J.S. (2002) The integrin alphavbeta6 binds and activates latent TGFbeta3. FEBS Letters, 511, 65-68. doi:10.1016/S0014-5793(01)03280-X

[113] Horan, G.S., et al. (2008) Partial inhibition of integrin alphavbeta6 prevents pulmonary fibrosis without exacerbating inflammation. American Journal of Respiratory and Critical Care Medicine, 177, 56-65. doi:10.1164/rccm.200706-805OC

[114] Wang, B., et al. (2007) Role of alphavbeta6 integrin in acute biliary fibrosis. Hepatology, 46, 1404-1412. doi:10.1002/hep.21849

[115] Huang, X.Z., et al. (1996) Inactivation of the integrin beta 6 subunit gene reveals a role of epithelial integrins in regulating inflammation in the lung and skin. The Journal of Cell Biology, 133, 921-928. doi:10.1083/jcb.133.4.921

[116] Puthawala, K., et al. (2008) Inhibition of integrin alphav beta6, an activator of latent transforming growth factor-beta, prevents radiation-induced lung fibrosis. American Journal of Respiratory and Critical Care Medicine, 177, 82-90. doi:10.1164/rccm.200706-806OC

[117] Davenpeck, K.L., Sterbinsky, S.A. and Bochner, B.S. (1998) Rat neutrophils express alpha4 and beta1 integrins and bind to vascular cell adhesion molecule-1 (VCAM-1) and mucosal addressin cell adhesion molecule-1 (MAdCAM-1). Blood, 91, 2341-2346.

[118] Jackson, D.Y. (2002) Alpha 4 integrin antagonists. Current Pharmaceutical Design, 8, 1229-1253.
[119] Hyun, Y.M., Lefort, C.T. and Kim, M. (2009) Leukocyte integrins and their ligand interactions. Immunologic Research, 45,195-208. doi:10.1007/s12026-009-8101-1

[120] Jackson, D.Y., et al. (1997) Potent alpha4beta 1 peptide antagonists as potential anti-inflammatory agents. Journal of Medicinal Chemistry, 40, 3359-3368. doi:10.1021/jm970175s

[121] Yacyshyn, B.R. (2008) Adhesion molecule therapeutics in IBD. Inflammatory Bowel Diseases, 14, S279-280.

[122] Gorfu, G., Rivera-Nieves, J. and Ley, K. (2009) Role of beta7 integrins in intestinal lymphocyte homing and retention. Current Molecular Medicine, 9, 836-850. doi:10.2174/156652409789105525

[123] von Andrian, U.H. and Mempel, T.R. (2003) Homing and cellular traffic in lymph nodes. Nature Reviews Immunology, 3, 867-878. doi:10.1038/nri1222

[124] Luster, A.D., Alon, R. and von Andrian, U.H. (2005) Immune cell migration in inflammation: Present and future therapeutic targets. Nature Immunology, 6, 11821190. doi: $10.1038 /$ ni1275

[125] Ley, K., et al. (2007) Getting to the site of inflammation: The leukocyte adhesion cascade updated. Nature Reviews Immunology, 7, 678-689. doi:10.1038/nri2156

[126] Lanzarotto, F., et al. (2006) Novel treatment options for inflammatory bowel disease: Targeting alpha 4 integrin. Drugs, 66, 1179-1189.

doi:10.2165/00003495-200666090-00002

[127] Sheremata, W.A., et al. (2005) The role of alpha-4 integrin in the aetiology of multiple sclerosis: Current knowledge and therapeutic implications. CNS Drugs, 19, 909-922. doi:10.2165/00023210-200519110-00002

[128] Yednock, T.A., et al. (1992) Prevention of experimental autoimmune encephalomyelitis by antibodies against alpha4beta 1 integrin. Nature, 356, 63-66. doi: $10.1038 / 356063 \mathrm{a} 0$

[129] Kingsley, G., Pitzalis, C. and Panayi, G.S. (1990) Immunogenetic and cellular immune mechanisms in rheumatoid arthritis: Relevance to new therapeutic strategies. British Journal of Rheumatology, 29, 58-64. doi:10.1093/rheumatology/29.1.58

[130] Barbadillo, C., et al. (1995) Anti-integrin immunotherapy in rheumatoid arthritis: Protective effect of anti-alpha4 antibody in adjuvant arthritis. Springer Seminars in Immunopathology, 16, 427-436. doi:10.1007/BF00196098

[131] Postigo, A.A., et al. (1992) Increased binding of synovial $\mathrm{T}$ lymphocytes from rheumatoid arthritis to endothelial-leukocyte adhesion molecule-1 (ELAM-1) and vascular cell adhesion molecule-1 (VCAM-1). Journal of Clinical Investigation, 89, 1445-1452. doi:10.1172/JCI115734

[132] Stoolman, L.M., (1989) Adhesion molecules controlling lymphocyte migration. Cell, 56, 907-910. doi:10.1016/0092-8674(89)90620-X

[133] Metzger, W.J. (1995) Therapeutic approaches to asthma based on VLA-4 integrin and its counter receptors. Seminars in Immunopathology, 16, 467-478. doi:10.1007/BF00196101

[134] Naclerio, R.M., et al. (1985) Inflammatory mediators in 
late antigen-induced rhinitis. The New England Journal of Medicine, 313, 65-70. doi:10.1056/NEJM198507113130201

[135] Humphries, M.J., et al. (1986) Identification of an alternatively spliced site in human plasma fibronectin that mediates cell type-specific adhesion. The Journal of Cell Biology, 103, 2637-2647. doi:10.1083/jcb.103.6.2637

[136] Guan, J.L. and Hynes, R.O. (1990) Lymphoid cells recognize an alternatively spliced segment of fibronectin via the integrin receptor alpha4beta1. Cell, 60, 53-61. doi:10.1016/0092-8674(90)90715-Q

[137] Stuve, O., et al. (2008) Alpha4-integrin antagonism with natalizumab: Effects and adverse effects. Journal of Neurology, 255, 58-65. doi:10.1007/s00415-008-6011-0

[138] Langer-Gould, A., et al. (2005) Progressive multifocal leukoencephalopathy in a patient treated with natalizumab. The New England Journal of Medicine, 353, 375381. doi:10.1056/NEJMoa051847

[139] Kleinschmidt-DeMasters, B.K. and Tyler, K.L. (2005) Progressive multifocal leukoencephalopathy complicating treatment with natalizumab and interferon beta-1a for multiple sclerosis. The New England Journal of Medicine, 353, 369-374. doi:10.1056/NEJMoa051782

[140] Van Assche, G., et al. (2005) Progressive multifocal leukoencephalopathy after natalizumab therapy for Crohn's disease. The New England Journal of Medicine, 353, 362368. doi:10.1056/NEJMoa051586

[141] Hauser, S.L. and Johnston, S.C. (2009) Balancing risk and reward: The question of natalizumab. Annals of Neurology, 66, A7-8. doi:10.1002/ana.21873

[142] Schowinsky, J., et al. Natalizumab-associated complication? First case of peripheral T cell lymphoma. Acta Neuropathologica, 123, 751-752. doi:10.1007/s00401-012-0967-7

[143] Schweikert, A., et al. (2009) Primary central nervous system lymphoma in a patient treated with natalizumab. Annals of Neurology, 66, 403-406. doi:10.1002/ana.21782

[144] Soler, D., et al. (2009) The binding specificity and selective antagonism of vedolizumab, an anti-alpha4beta7 integrin therapeutic antibody in development for inflamematory bowel diseases. Journal of Pharmacology and Experimental Therapeutics, 330, 864-875. doi:10.1124/jpet.109.153973

[145] Singh, J., et al. (2004) Rational design of potent and selective VLA-4 inhibitors and their utility in the treatment of asthma. Current Topics in Medicinal Chemistry, 4, 1497-1507. doi:10.2174/1568026043387520

[146] Ravensberg, A.J., et al. (2006) The effect of a single inhaled dose of a VLA-4 antagonist on allergen-induced airway responses and airway inflammation in patients with asthma. Allergy, 61, 1097-1103. doi:10.1111/j.1398-9995.2006.01146.x

[147] Humphries, J.D., Byron, A. and Humphries, M.J. (2006) Integrin ligands at a glance. Journal of Cell Science, 119, 3901-3903. doi:10.1242/jcs.03098

[148] Magnussen, A., et al. (2005) Rapid access of antibodies to alpha5betal integrin overexpressed on the luminal sur- face of tumor blood vessels. Cancer Research, 65, 27122721. doi:10.1158/0008-5472.CAN-04-2691

[149] Parsons-Wingerter, P., et al. (2005) Uniform overexpression and rapid accessibility of alpha5betal integrin on blood vessels in tumors. American Journal of Pathology, 167, 193-211. doi:10.1016/S0002-9440(10)62965-3

[150] Kita, D., et al. (2001) Expression of dominant-negative form of Ets-1 suppresses fibronectin-stimulated cell adhesion and migration through down-regulation of integrin alpha5 expression in U251 glioma cell line. Cancer Research, 61, 7985-7991.

[151] Gong, J., et al. (1997) Role of alpha5beta1 integrin in determining malignant properties of colon carcinoma cells. Cellular differentiation, 8, 83-90.

[152] Smallheer, J.M., et al. (2004) Synthesis and biological evaluation of nonpeptide integrin antagonists containing spirocyclic scaffolds. Bioorganic \& Medicinal Chemistry Letters, 14, 383-387. doi:10.1016/j.bmcl.2003.10.057

[153] Maglott, A., et al. (2006) The small alpha5beta1 integrin antagonist, SJ749, reduces proliferation and clonogenicity of human astrocytoma cells. Cancer Research, 66, 60026007. doi:10.1158/0008-5472.CAN-05-4105

[154] Umeda, N., et al. (2006) Suppression and regression of choroidal neovascularization by systemic administration of an alpha5betal integrin antagonist. Molecular Pharmacology, 69, 1820-1828. doi:10.1124/mol.105.020941

[155] Pastor, J.C., de la Rua, E.R. and Martin, F. (2002) Proliferative vitreoretinopathy: Risk factors and pathobiology. Progress in Retinal and Eye Research, 21, 127-144. doi:10.1016/S1350-9462(01)00023-4

[156] Casaroli-Marano, R.P., Pagan, R. and Vilaro, S. (1999) Epithelial-mesenchymal transition in proliferative vitreoretinopathy: Intermediate filament protein expression in retinal pigment epithelial cells. Investigative Ophthalmology \& Visual Science, 40, 2062-2072.

[157] Jin, M., et al. (2000) Promotion of adhesion and migration of RPE cells to provisional extracellular matrices by TNF-alpha. Investigative Ophthalmology \& Visual Science, 41, 4324-4332.

[158] Okazaki, T., et al. (2009) Alpha5beta1 Integrin blockade inhibits lymphangiogenesis in airway inflammation. American Journal of Pathology, 174, 2378-2387. doi:10.2353/ajpath.2009.080942

[159] Witte, M.H., et al. (2006) Structure function relationships in the lymphatic system and implications for cancer biology. Cancer and Metastasis Reviews, 25, 159-184. doi:10.1007/s10555-006-8496-2

[160] Randolph, G.J., Angeli, V. and Swartz, M.A. (2005) Dendritic-cell trafficking to lymph nodes through lymphatic vessels. Nature Reviews Immunology, 5, 617-628. doi: $10.1038 /$ nri1670

[161] Zhang, X., Groopman, J.E. and Wang, J.F. (2005). Extracellular matrix regulates endothelial functions through interaction of VEGFR-3 and integrin alpha5beta1. Journal of Cellular Physiology, 202, 205-214. doi:10.1002/jep.20106

[162] Dietrich, T., et al. (2007) Inhibition of inflammatory lymphangiogenesis by integrin alpha5 blockade. Ameri- 
can Journal of Pathology, 171, 361-372. doi:10.2353/ajpath.2007.060896

[163] Ricart, A.D., et al. (2008) Volociximab, a chimeric monoclonal antibody that specifically binds alpha5beta 1 integrin: A phase I, pharmacokinetic, and biological correlative study. Clinical Cancer Research, 14, 7924-7929. doi:10.1158/1078-0432.CCR-08-0378

[164] Livant, D.L., et al. (2000) Anti-invasive, antitumorigenic, and antimetastatic activities of the PHSCN sequence in prostate carcinoma. Cancer Research, 60, 309-320.

[165] Bouvard, D., et al. (2001) Functional consequences of integrin gene mutations in mice. Circulation Research, 89, 211-223. doi:10.1161/hh1501.094874

[166] Varner, J.A. and Cheresh, D.A. (1996) Integrins and cancer. Current Opinion in Cell Biology, 8, 724-730. doi:10.1016/S0955-0674(96)80115-3

[167] Reynolds, L.E., et al. (2002) Enhanced pathological angiogenesis in mice lacking beta3 integrin or beta3 and beta5 integrins. Nature Medicine, 8, 27-34. doi: $10.1038 / \mathrm{nm} 0102-27$

[168] Senger, D.R., et al. (2002) The alphalbeta1 and alpha2beta1 integrins provide critical support for vascular endothelial growth factor signaling, endothelial cell migration, and tumor angiogenesis. American Journal of Pathology, 160, 195-204.

doi:10.1016/S0002-9440(10)64363-5

[169] Goh, K.L., Yang, J.T. and Hynes, R.O. (1997) Mesodermal defects and cranial neural crest apoptosis in alpha5 integrin-null embryos. Development, 124, 4309-4319.

[170] Bader, B.L., et al. (1998) Extensive vasculogenesis, angiogenesis, and organogenesis precede lethality in mice lacking all alpha v integrins. Cell, 95, 507-519. doi:10.1016/S0092-8674(00)81618-9

[171] Legler, D.F., et al. (2001) Superactivation of integrin alphavbeta3 by low antagonist concentrations. Journal of Cell Science, 114, 1545-1553.

[172] Reynolds, A.R., et al. (2009) Stimulation of tumor growth and angiogenesis by low concentrations of RGDmimetic integrin inhibitors. Nature Medicine, 15, 392400. doi:10.1038/nm.1941

[173] Carmeliet, P., (2002) Integrin indecision. Nature Medicine, 8, 14-16. doi:10.1038/nm0102-14

[174] Smith, J.J., Sorensen, A.G. and Thrall, J.H. (2003) Biomarkers in imaging: Realizing radiology's future. Radiology, 227, 633-638. doi:10.1148/radiol.2273020518

[175] Beer, A.J. and Schwaiger, M. (2008) Imaging of integrin alphavbeta3 expression. Cancer and Metastasis Reviews, 27, 631-644. doi:10.1007/s10555-008-9158-3

[176] McDonald, D.M. and Choyke, P.L. (2003) Imaging of angiogenesis: From microscope to clinic. Nature Medicine, 9, 713-725. doi:10.1038/nm0603-713

[177] Rudin, M. and Weissleder, R. (2003) Molecular imaging in drug discovery and development. Nature Reviews Drug Discovery, 2, 123-131. doi:10.1038/nrd1007

[178] Wadas, T.J., et al. (2009) Targeting the alphavbeta3 integrin for small-animal PET/CT of osteolytic bone metastases. Journal of Nuclear Medicine, 50, 1873-1880. doi:10.2967/jnumed.109.067140

[179] Friedlander, M., et al. (1996) Involvement of integrins alphavbeta3 and alphavbeta5 in ocular neovascular diseases. Proceedings of the National Academy of Sciences of the United States of America, 93, 9764-9769. doi:10.1073/pnas.93.18.9764

[180] Kotys, M.S., et al. (2009) Profile order and time-dependent artifacts in contrast-enhanced coronary MR angiography at 3T: Origin and prevention. Magnetic Resonance in Medicine, 62, 292-299. doi:10.1002/mrm.21997

[181] Chen, X., et al. (2004) Pegylated Arg-Gly-Asp peptide: $64 \mathrm{Cu}$ labeling and PET imaging of brain tumor alphavbeta3-integrin expression. Journal of Nuclear Medicine, 45, 1776-1783.

[182] Wu, Y., et al. (2005) MicroPET imaging of glioma integrin alphavbeta3 expression using (64)Cu-labeled tetrameric RGD peptide. Journal of Nuclear Medicine, 46, 1707-1718.

[183] Cai, W., et al. (2006) In vitro and in vivo characterization of 64Cu-labeled Abegrin, a humanized monoclonal antibody against integrin alphavbeta3. Cancer Research, 66, 9673-9681. doi:10.1158/0008-5472.CAN-06-1480

[184] Kimura, R.H., et al. (2009) Engineered knottin peptides: A new class of agents for imaging integrin expression in living subjects. Cancer Research, 69, 2435-2442. doi:10.1158/0008-5472.CAN-08-2495

[185] Hamidi, S., et al. (2000) Expression of alphavbeta6 integrin in oral leukoplakia. British Journal of Cancer, 82, 1433-1440. doi:10.1054/bjoc.1999.1130

[186] Hausner, S.H., et al. (2009) Targeted in vivo imaging of integrin alpha $\mathrm{v}$ beta 6 with an improved radiotracer and its relevance in a pancreatic tumor model. Cancer Research, 69, 5843-5850. doi:10.1158/0008-5472.CAN-08-4410

[187] Liu, Z., et al. (2007) In vivo biodistribution and highly efficient tumour targeting of carbon nanotubes in mice. Nature Nanotechnology, 2, 47-52. doi:10.1038/nnano.2006.170

[188] Schmieder, A.H., et al. (2008) Three-dimensional MR mapping of angiogenesis with alpha5beta1(alphavbeta3)targeted theranostic nanoparticles in the MDA-MB-435 xenograft mouse model. The FASEB Journal, 22, 41794189. doi:10.1096/fj.08-112060

[189] Daldrup-Link, H.E., Simon, G.H. and Brasch, R.C. (2006) Imaging of tumor angiogenesis: Current approaches and future prospects. Current Pharmaceutical Design, 12, 2661-2672. doi:10.2174/138161206777698774

[190] Kaufmann, B.A. and Lindner, J.R. (2007) Molecular imaging with targeted contrast ultrasound. Current Opinion in Biotechnology, 18, 11-16. doi:10.1016/j.copbio.2007.01.004

[191] Willmann, J.K., et al. (2010) Targeted contrast-enhanced ultrasound imaging of tumor angiogenesis with contrast microbubbles conjugated to integrin-binding knottin peptides. Journal of Nuclear Medicine, 51, 433-440. doi:10.2967/jnumed.109.068007

[192] Chen, X., Conti, P.S. and Moats, R.A. (2004) In vivo near-infrared fluorescence imaging of integrin alphav 
beta3 in brain tumor xenografts. Cancer Research, 64, 8009-8014. doi:10.1158/0008-5472.CAN-04-1956

[193] von Wallbrunn, A., et al. (2007) In vivo imaging of integrin alphavbeta3 expression using fluorescence-mediated tomography. European Journal of Nuclear Medicine and Molecular, 34, 745-754. doi:10.1007/s00259-006-0269-1

[194] Cai, W. Hsu, A. R., Li, Z.-B. and Chen, X.Y. (2007) Are quantum dots ready for in vivo imaging in human subjects? Nanoscale Research Letters, 2, 265-281. doi:10.1007/s11671-007-9061-9

[195] Wang, Z., Chui, W.K and Ho, P.C. (2010) Integrin targeted drug and gene delivery. Expert Opinion on Drug Delivery, 7, 159-171. doi:10.1517/17425240903468696

[196] Arap, W., Pasqualini, R. and Ruoslahti, E. (1998) Cancer treatment by targeted drug delivery to tumor vasculature in a mouse model. Science, 279, 377-380.

[197] Burkhart, D.J., et al. (2004) Doxorubicin-formaldehyde conjugates targeting alphavbeta3 integrin. Molecular Cancer Therapeutics, 3, 1593-1604.

[198] Chen, X., et al. (2005) Synthesis and biological evaluation of dimeric RGD peptide-paclitaxel conjugate as a model for integrin-targeted drug delivery. Journal of Medicinal Chemistry, 48, 1098-1106. doi:10.1021/jm049165z

[199] Pilkington-Miksa, M., et al. (2012) Design, synthesis, and biological evaluation of novel cRGD-paclitaxel conjugates for integrin-assisted drug delivery. Bioconjugate Chemistry, 23, 1610-1622. doi:10.1021/bc300164t

[200] Curnis, F., et al. (2004) Coupling tumor necrosis factor-alpha with alphav integrin ligands improves its antineoplastic activity. Cancer Research, 64, 565-571. doi:10.1158/0008-5472.CAN-03-1753

[201] Danhier, F., et al. (2009) Targeting of tumor endothelium by RGD-grafted PLGA-nanoparticles loaded with pacli- taxel. Journal of Controlled Release, 140, 166-173. doi:10.1016/j.jconrel.2009.08.011

[202]Zhou, H.F., et al. (2009) Alphavbeta3-targeted nanotherapy suppresses inflammatory arthritis in mice. The FASEB Journal, 23, 2978-2985. doi:10.1096/fj.09-129874

[203] Hood, J.D., et al. (2002) Tumor regression by targeted gene delivery to the neovasculature. Science, 296, 24042407. doi:10.1126/science. 1070200

[204] Bhattacharyya, J., et al. (2009) Single subcutaneous administration of RGDK-lipopeptide: rhPDGF-B gene complex heals wounds in streptozotocin-induced diabetic rats Molecular Pharmaceutics, 6, 918-927. doi: $10.1021 / \mathrm{mp} 800231 \mathrm{z}$

[205] Peer, D. and Shimaoka, M. (2009) Systemic siRNA delivery to leukocyte-implicated diseases. Cell Cycle, 8 , 853-859. doi:10.4161/cc.8.6.7936

[206] Waite, C.L. and Roth, C.M. (2009) Pamam-Rgd conjugates enhance siRNA delivery through a multicellular spheroid model of malignant glioma. Bioconjugate Chemistry, 20, 1908-1916. doi:10.1021/bc900228m

[207] Lemieux, J.M., Horowitz, M.C. and Kacena, M.A. (2010) Involvement of integrins alpha3beta1 and alpha5beta1 and glycoprotein IIb in megakaryocyte-induced osteoblast proliferation. Journal of Cellular Biochemistry, 109 927-932.

[208] Cordes, N. and Park, C.C. (2007) Betal integrin as a molecular therapeutic target. International Journal of Radiation Biology, 83, 753-760. doi:10.1080/09553000701639694

[209] Haubner, R., et al. (2005) Noninvasive visualization of the activated alphavbeta3 integrin in cancer patients by positron emission tomography and [18F]Galacto-RGD. PLOS Medicine, 2, e70. 